\title{
Resurrection and re-description of Plethodontohyla laevis (Boettger, 1913) and transfer of Rhombophryne alluaudi (Mocquard, 1901) to the genus Plethodontohyla (Amphibia, Microhylidae, Cophylinae)
}

\author{
Adriana Bellati ${ }^{1,{ }^{*}}$, Mark D. Scherz ${ }^{2, *}$, Steven Megson ${ }^{3}$, Sam Hyde Roberts ${ }^{4}$, \\ Franco Andreone ${ }^{5}$, Gonçalo M. Rosa ${ }^{6,7,8}$, Jean Noë $1^{9}$, Jasmin E. Randrianirina ${ }^{10}$, \\ Mauro Fasola ${ }^{1}$, Frank Glaw ${ }^{2}$, Angelica Crottini ${ }^{11}$ \\ 1 Dipartimento di Scienze della Terra e dell'Ambiente, Università di Pavia, Via Ferrata 1, I-27100 Pavia, Italy \\ 2 Zoologische Staatssammlung München (ZSM-SNSB), Münchhausenstr. 21, 81247 München, Germany \\ 3 School of Science and the Environment, Manchester Metropolitan University, Manchester, M1 5GD, UK \\ 4 SEED Madagascar, Studio 7, 1 A Beethoven Street, London, W10 4LG, UK \\ 5 Museo Regionale di Scienze Naturali, Sezione di Zoologia, Via G. Giolitti, 36, I-10123, Torino, Italy \\ 6 Department of Biology, University of Nevada, Reno, Reno NV 89557, USA \\ 7 Institute of Zoology, Zoological Society of London, Regent's Park, London, NW1 4RY, UK \\ 8 Centre for Ecology, Evolution and Environmental Changes (CE3C), Faculdade de Ciências da Universidade de Lisboa, Bloco C2, \\ Campo Grande, 1749-016 Lisboa, Portugal \\ 9 Madagascar Fauna and Flora Group, BP 442, Morafeno, Toamasina 501, Madagascar \\ 10 Parc Botanique et Zoologique de Tsimbazaza, BP 4096, Antananarivo 101, Madagascar \\ 11 CIBIO, Research Centre in Biodiversity and Genetic Resources, InBIO, Universidade do Porto, Campus Agrário de Vairão, Rua Padre \\ Armando Quintas, $N^{\circ}$ 7, 4485-661 Vairão, Portugal \\ http://zoobank.org/AFA6C1FE-1627-408B-9684-F6240716C62B
}

Corresponding author: Angelica Crottini (tiliquait@yahoo.it)

Received 26 June 2017

Accepted 19 January 2018

Published 2 February 2018

Academic editor:

Johannes Penner

\section{Key Words}

Amphibia

Anura

Phrynocara laeve

Plethodontohyla alluaudi

Madagascar

Integrative taxonomy

\begin{abstract}
The systematics of the cophyline microhylid frog genera Plethodontohyla and Rhombophryne have long been intertwined, and their relationships have only recently started to become clear. While Rhombophryne has received a lot of recent taxonomic attention, Plethodontohyla has been largely neglected. Our study is a showcase of just how complex the taxonomic situation between these two genera is, and the care that must be taken to resolve taxonomic conundrums where old material, multiple genus transitions, and misattribution of new material obfuscate the picture. We assessed the identity of the historic names Dyscophus alluaudi (currently in the genus Rhombophryne), Phrynocara laeve and Plethodontohyla laevis tsianovohensis (both synonyms of Rhombophryne alluaudi) based on an integrative taxonomic approach harnessing genetics, external morphology, osteological data obtained via micro-Computed Tomography (micro-CT) and bioacoustics. We show that (1) the holotype of Dyscophus alluaudi is a member of the genus Plethodontohyla; (2) the Rhombophryne specimens from central Madagascar currently assigned to Rhombophryne alluaudi have no affinity with that species, and are instead an undescribed species; and (3) Phrynocara laeve and Dyscophus alluaudi are not synonymous, but represent closely related species, whereas Plethodontohyla laevis tsianovohensis is tentatively confirmed as synonym of $D$. alluaudi. We resurrect and re-describe Plethodontohyla laevis, and re-allocate and re-describe Plethodontohyla alluaudi on the basis of new and historic material.
\end{abstract}

* Both authors contributed equally 


\section{Introduction}

The microhylid subfamily Cophylinae Cope, 1889, endemic to Madagascar, is today recognised as possessing eight genera according to Scherz et al. (2016a): Plethodontohyla Boulenger, 1882, Rhombophryne Boettger, 1880, Stumpffia Boettger, 1881, Madecassophryne Guibé, 1974, Platypelis Boulenger, 1882, Anodonthyla Müller, 1892, Cophyla Boettger, 1880 and Anilany Scherz, Vences, Rakotoarison, Andreone, Köhler, Glaw \& Crottini, 2016. Recent studies (Vieites et al. 2009, Perl et al. 2014) have provided DNA barcoding reference sequences for almost all described and undescribed frog species of Madagascar and have highlighted the presence of a large taxonomic gap in the Cophylinae, which currently comprises over 100 described species (Scherz et al. 2016a, AmphibiaWeb 2018), but which has an estimated further $>40$ species yet to be formally described. In spite of the recent efforts in revising the systematics of this subfamily (e.g. D'Cruze et al. 2010, Glaw et al. 2010, Rakotoarison et al. 2012, 2015, 2017, Rosa et al. 2014, Scherz et al. 2016b, Lambert et al. 2017), the genus Plethodontohyla has been relatively neglected.

Plethodontohyla in its most updated definition (Wollenberg et al. 2008, Scherz et al. 2016a) comprises moderately small to large terrestrial or scansorial forest frogs (snout-vent length [SVL] 25-100 mm, Glaw and Vences $2007 b$ ). Despite sharing a large number of morphological features (e.g. the presence of connected lateral metatarsalia, vomerine teeth, inner [and sometimes outer] metatarsal tubercles, short hindlimbs and males with a single subgular vocal sac; Scherz et al. 2016a), an osteological circumscription to the genus still remains difficult. The ecomorphologies correlate with different skeletal adaptations; for instance, all semi-arboreal taxa ( $P$. notosticta, $P$. mihanika) and three predominantly terrestrial species ( $P$. guentheri, $P$. inguinalis and $P$. fonetana) possess expanded terminal phalanges (T- or Y-shaped), while all other terrestrial and fossorial taxa possess knob-shaped terminal phalanges. Whereas the clavicle is always absent or highly reduced in terrestrial or fossorial species, it can be present or absent in arboreal species, suggesting repeated loss of these bones (Scherz et al. 2016a, unpublished data), but also the monophyly of these phenetic groups (arboreal and terrestrial/fossorial) has yet to be established. In addition to being a morphologically diverse genus, Plethodontohyla has had an exceptionally convoluted taxonomic history.

Plethodontohyla was originally erected by Boulenger (1882) to contain Callula notosticta Günther, 1877 (the type species of the genus), P. inguinalis Boulenger, 1882 and $P$. brevipes Boulenger, 1882. This circumscription was before its time in recognizing the phenotypic diversity of Plethodontohyla, as Boulenger (1882) established the genus containing terrestrial/fossorial ( $P$. brevipes) and arboreal and semi-terrestrial ( $P$. notosticta, $P$. inguinalis) species. Peters (1883) later erected two genera, Phrynocara Peters, 1883 (type species Ph. tuberatum
Peters, 1883) and Mantipus Peters, 1883 (type species M. hildebrandti Peters, 1883), each monotypic. Some years later Mocquard (1895) erected another monotypic genus, Mantiphrys Mocquard, 1895 (type species Mantiphrys laevipes Mocquard, 1895). Over the 20th century, six more species of the genus Plethodontohyla were described, plus two in the genus Phrynocara and seven in Mantipus. Noble and Parker (1926) synonymised Mantiphrys with Mantipus, and Phrynocara with Plethodontohyla, and transferred P. inguinalis to Mantipus. Guibé contributed repeatedly to the species-level taxonomy of these genera (e.g. Guibé 1947, 1974, 1975), but made only one small change at genus-level, which he later reversed (Guibé 1947, 1952, 1978; see below). Blommers-Schlösser and Blanc (1991) later synonymised Mantipus with Plethodontohyla in their comprehensive monograph on the amphibians of Madagascar (Mantipus hildebrandti becoming a junior synonym of Plethodontohyla inguinalis). At this point, the genus Plethodontohyla contained twelve nominal species, encompassing a wide range of ecomorphologies (terrestrial, fossorial and semi-arboreal) and sizes, from the $22 \mathrm{~mm} P$. minuta to the $100 \mathrm{~mm}$ P. inguinalis.

Andreone et al. (2005) produced the first comprehensive molecular dataset for the subfamily Cophylinae, where it became clear that several members of the genus Plethodontohyla were more closely related to Rhombophryne testudo Boettger, 1880 — which had, until that point, been alone in the monotypic genus Rhombophryne-but refrained from making any taxonomic arrangements until more data were available. Frost et al. (2006) also recovered the paraphyly of Plethodontohyla first identified by Andreone et al. (2005), and transferred three species to Rhombophryne ( $R$. alluaudi, $R$. coudreaui and $R$. laevipes). Based on the more comprehensive molecular analysis of the subfamily (Wollenberg et al. 2008) another four species ( $R$. minuta, $R$. coronata, $R$. guentherpetersi, $R$. serratopalpebrosa) were transferred to Rhombophryne (Glaw and Vences 2007b). Since then, no more species have moved between these two genera except $R$. matavy which was erroneously transferred to Plethodontohyla by Peloso et al. (2016), but returned to Rhombophryne by Scherz et al. (2016a).

The taxon Dyscophus alluaudi Mocquard, 1901 was originally described with the type locality 'Fort Dauphin' (or Tolagnaro; Fig. 1), but was later transferred to Plethodontohyla by Noble and Parker (1926). It was then moved to Mantipus by Guibé (1947), but was later returned by him to Plethodontohyla without comment (Guibé 1978), presumably based on the similarity of its pectoral girdle to that of Mantipus angeli Guibé, 1947, which he synonymised with Plethodontohyla tuberata (Guibé 1952). Another taxon, Phrynocara laeve Boettger, 1913, was described from Sakana, East Madagascar, a locality reported to be a magnificently preserved piece of jungle (Boettger 1913). This taxon was transferred to Plethodontohyla by Noble and Parker (1926), initially with an incorrect emendation (Plethodontohyla laeve), 


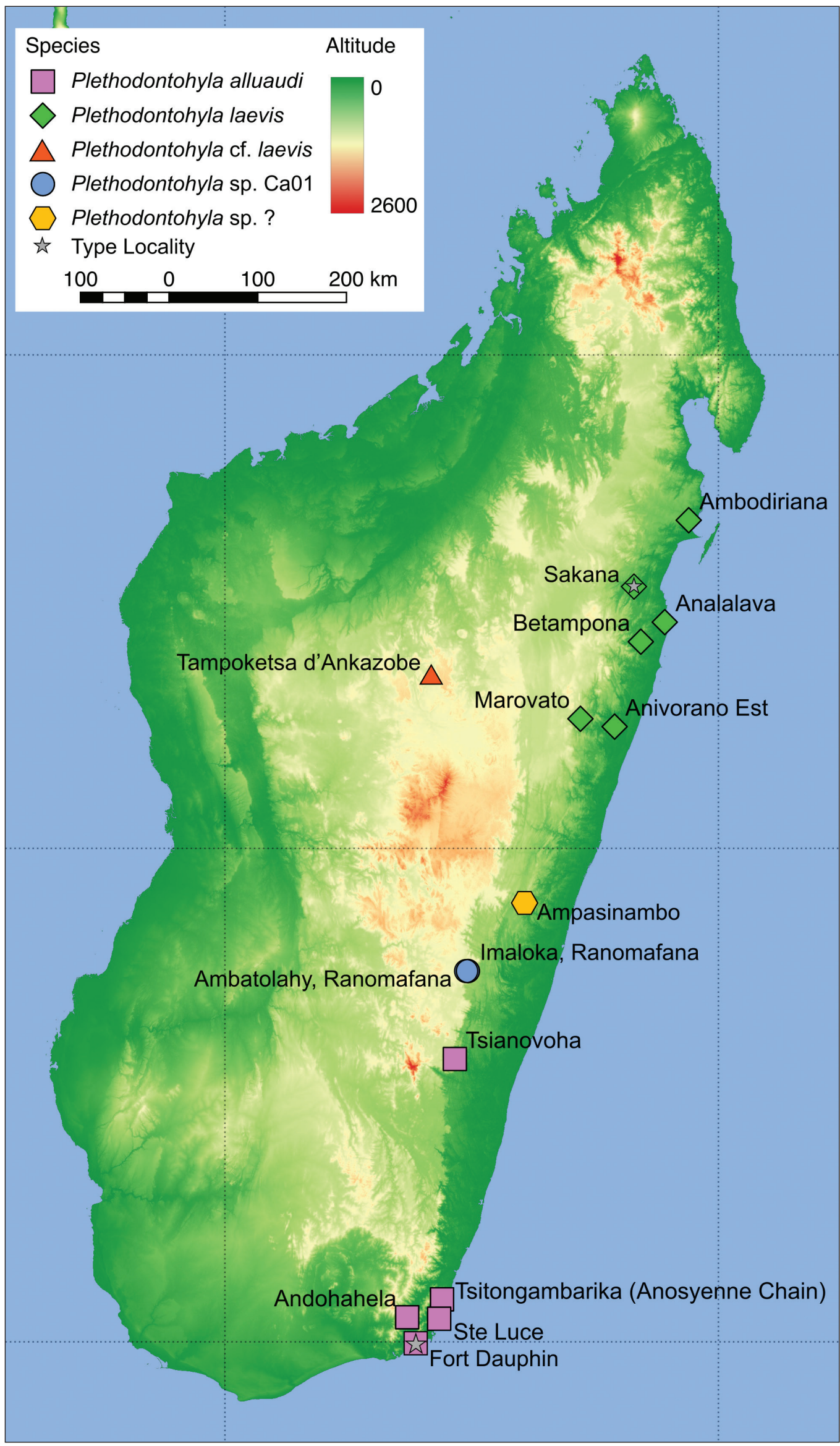

Figure 1. Locality records of Plethodontohyla laevis, $P$. alluaudi, and $P$. sp. Ca01, including the uncertain records of two members of this complex (P. cf. laevis and $P$. sp.) from Blommers-Schlösser (1975). 
later corrected to P. laevis by Parker (1934). A supposed subspecies of Plethodontohyla laevis, P. l. tsianovohensis Angel, 1936, was later described from Tsianovoha

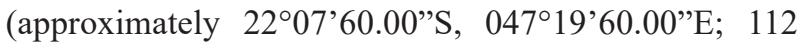
$\mathrm{m}$ above sea level [a.s.l.], collected by R. Heim between 1934 and 1935, Fig. 1), a lowland forest in the Vatovavy-Fitovinavy region in eastern Madagascar, but was synonymised with P. laevis by Guibé (1978). Plethodontohyla laevis was then synonymised with $P$. alluaudi by Blommers-Schlösser and Blanc (1991). Following Blommers-Schlösser (1975), who assigned a specimen collected in Mandraka to Mantipus alluaudi, Glaw and Vences (1992), in their first edition of the field guide to the amphibians and reptiles of Madagascar, attributed a specimen of a cophyline frog from Andasibe in central eastern Madagascar also to $P$. alluaudi. Subsequently collected specimens from this region became the genetic reference material for the taxon (Andreone et al. 2005). On the basis of genetic data from these specimens, $P$. alluaudi was transferred to Rhombophryne by Frost et al. (2006), where it has since remained.

Recently, individuals of a species of terrestrial cophyline microhylid were found in Betampona Special Reserve (Fig. 1), a small but relatively well-maintained lowland rainforest fragment in eastern Madagascar (Rosa et al. 2012). Genetic analysis revealed these specimens to belong to the genus Plethodontohyla, and they were referred to as $P$. sp. Ca3 by Vieites et al. (2009) and Scherz et al. (2016a) (also called P. sp. aff. brevipes [Ca FJ559294] by Rosa et al. 2012).

In this study, we examined these specimens from Betampona, and found them to have strong affinities with the holotype of Phrynocara laeve. This suggested that at least Phrynocara laeve was incorrectly attributed to the genus Rhombophryne, and prompted questions regarding the genus-level assignment of Dyscophus alluaudi. To resolve these questions, we investigated the morphology and osteology of the type material of Dyscophus alluaudi, Phrynocara laeve, and Plethodontohyla laevis tsianovohensis (Fig. 2). We then studied the morphology, osteology and genetics of the Rhombophryne species from Andasibe currently assigned to $R$. alluaudi, recently collected material of $P$. sp. Ca3 from Betampona, and of specimens of ' $R$. alluaudi' from near Tolagnaro. We base our study on the integration of data from external and internal (osteological) morphology, natural history, congruence between mitochondrial and nuclear DNA differentiation and bioacoustic analyses.

\section{Materials and methods}

In anticipation of the main outcomes of our research, we hereafter use Plethodontohyla laevis and P. alluaudi in reference to these two names, except when discussing the type material, where we refer to the species by their original names (Phrynocara laeve and Dyscophus alluaudi, respectively).

\section{Voucher specimen collection}

New specimens were collected either during the day by searching the leaf litter, or at night using torches and headlamps, sometimes guided by the male advertisement call. Representative voucher specimens were euthanized, and then fixed in $90 \%$ ethanol or $10 \%$ buffered formalin, rinsed in water and preserved in $70 \%$ ethanol. Live colouration was photographed at the time of capture.

Locality information were recorded using a GPS, datum WGS84. Field numbers FAZC, ACZC and ACZCV, FGZC, and PBZT-RJS refer to F. Andreone, A. Crottini, F. Glaw, and J.E. Randrianirina, respectively. Tissue samples (taken before specimen fixation) were obtained from hindlimb muscle or tongue, and preserved separately in $99 \%$ ethanol.

Institutional abbreviations used herein are as follows: $\mathrm{ZSM}=$ Zoologische Staatssammlung München, Germany; SMF = Naturmuseum Senckenberg in Frankfurt am Main, Germany; UADBA-A = Amphibian collections of the Université d'Antananarivo Département de Biologie Animale, Madagascar (currently Mention Zoologie et Biodiversité Animale, Faculté des Sciences, Université d'Antananarivo, Antananarivo); MRSN = Museo Regionale di Scienze Naturali, Torino, Italy; MNHN = Muséum National d'Histoire Naturelle de Paris, France; ZFMK = Zoologisches Forschungsmuseum Alexander Koenig, Bonn, Germany; ZMA = Zoölogisch Museum Amsterdam (transferred to Naturalis Biodiversity Center in Leiden), Netherlands; BMNH = Natural History Museum, London, United Kingdom.

\section{Morphological measurements}

Measurements of preserved specimens were taken by MDS with a calliper to the nearest $0.01 \mathrm{~mm}$, rounded to the nearest $0.1 \mathrm{~mm}$ (ratios calculated before rounding to avoid compound rounding errors): SVL (snout-vent length), HW (maximum head width), HL (head length, from the rictus to the snout tip), ED (horizontal eye diameter), END (eye-nostril distance), NSD (nostril-snout tip distance), NND (internarial distance), TD (horizontal tympanum diameter), HAL (hand length, from the radioulnar-carpal articulation to the tip of the longest finger), FORL (forelimb length, given by the sum of HAL, lower arm length [LAL] and upper arm length [UAL]), FOL (foot length, from the tarsal-metatarsal articulations to the tip of the longest toe), TARL (tarsus length), FOTL (foot length including tarsus, given by the sum of FOL and TARL), TIBL (tibia length), HIL (hind-limb length, given by the sum of FOL, TARL, TIBL and thigh length [THIL]), IMCL (maximum length of inner metacarpal tubercle). Examined specimens are listed in Table 1. Note that measurements of Plethodontohyla brevipes are from specimens that match the original description of that species in having a uniform brown dorsum and slightly granular dorsal skin. Terminology and description scheme follow Vences et al. (2003), Glaw and Vences (2007a) and Glaw et al. (2007) to allow for better comparison to other Plethodontohyla species. 
a
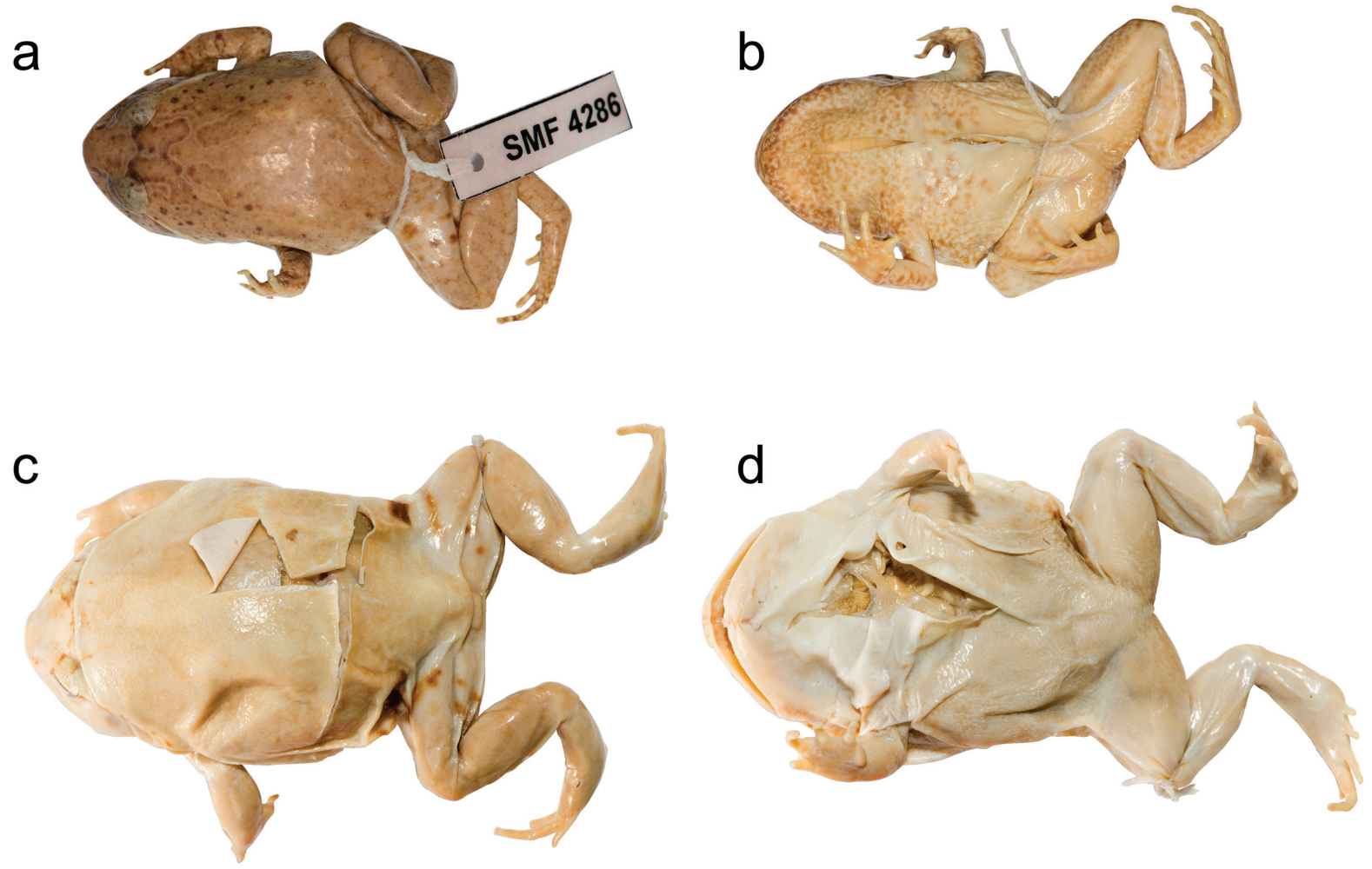

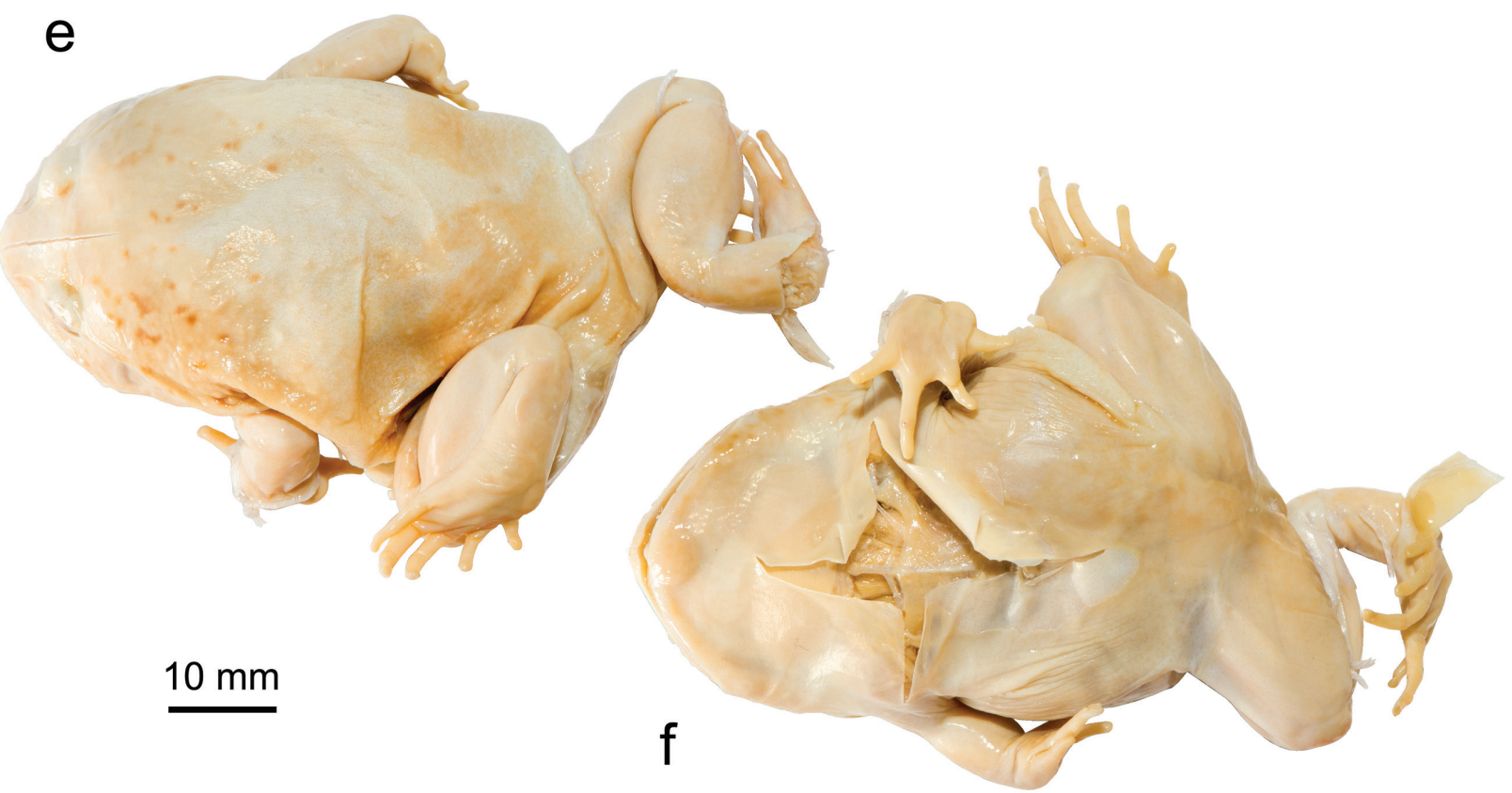

Figure 2. Photographs of the holotypes of (a-b) Phrynocara laeve (SMF 4286), (c-d) Dyscophus alluaudi (MNHN 1901.235) and (e-f) Plethodontohyla laevis tsianovohensis (MNHN 1936.47) in dorsal (a, c, e) and ventral (b, d, f) view.

\section{Osteological analyses}

The holotypes of Phrynocara laeve (SMF 4286), Dyscophus alluaudi (MNHN 1901.235) and Plethodontohyla laevis tsianovohensis (MNHN 1936.47), and one specimen assigned below to Plethodontohyla laevis (MRSN A6340) from Betampona, one specimen

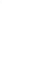




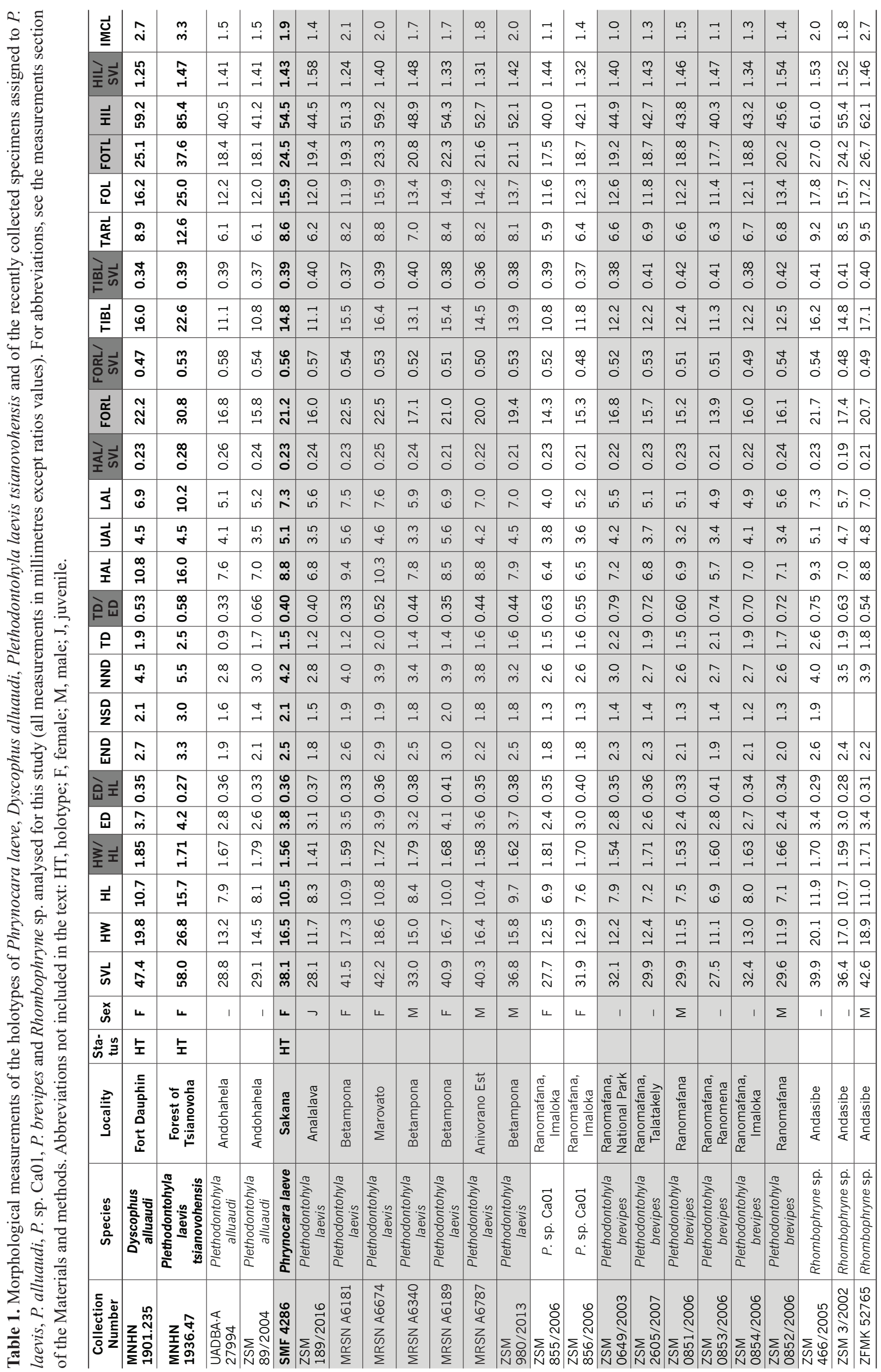



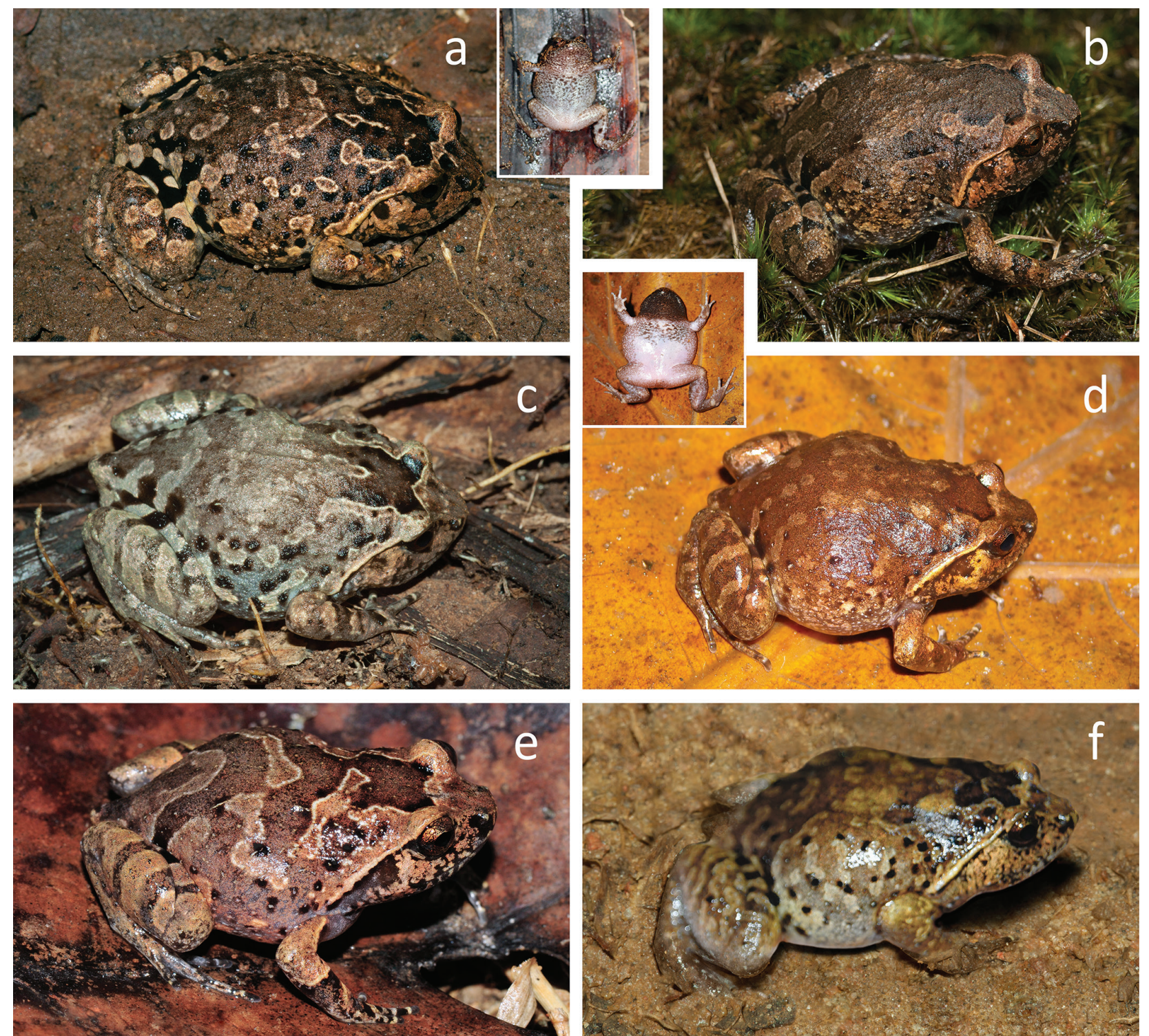

Figure 3. Individuals of Plethodontohyla laevis in life, illustrating the diversity of colour patterns from different sites of the species known distribution range: (a) MRSN A6188 from Betampona in dorsolateral and (inset) ventral view; (b) MRSN A6181 from Betampona in dorsolateral view; (c) FAZC 13898 from Betampona in dorsolateral view (Photos by Gonçalo M. Rosa); (d) MRSN A6787 from Anivorano Est in dorsolateral and (inset) ventral view (Photo by Jasmin E. Randrianirina); (e) ZSM 189/2016 from Analalava-Foulpointe in dorsolateral view (Photo by Frank Glaw); (f) individual (not collected) from Ambodiriana in dorsolateral view (Photo by Lauric Reynes).

for Madagascan microhylids (e.g. Scherz et al. 2014, 2015a, b, 2016a, b , 2017). The specimens were scanned individually at $140 \mathrm{kV}$ and $80 \mu \mathrm{A}$, with a timing of $750 \mathrm{~ms}$, for a total of 20 or 30 minutes (1440 or 2440 images respectively). Reconstruction methods were the same as those used previously (see the aforementioned literature, and especially Scherz et al. 2017). Examination of the internal anatomy of the specimens was conducted in VG STUDIO MAX 2.2 (Volume Graphics GmbH, Heidelberg, Germany). DICOM stacks of the scans and rotational videos are deposited in MorphoSource at the following URL: http://morphosource.org/Detail/ ProjectDetail/Show/project_id/396. Portable document file (PDF)-embedded 3D models of select specimens were produced using AMIRA 6.1 (FEI Visualization
Sciences Group, Burlington, MA), and are provided as digital Suppl. materials 1-6. Osteological terminology follows Trueb (1968, 1973).

\section{Molecular analyses}

Ten samples of $P$. laevis from four different localities (Fig. 3) (seven from Betampona Natural Reserve, one from Marovato, one from Anivorano Est and one from near Analalava-Foulpointe); three samples of $P$. alluaudi (in its new definition but until now referred to as ' $P$. bipunctata'; Fig. 4a) from Andohahela (EU341068, Wollenberg et al. 2008), Tsitongambarika (Anosyenne Chain) and Sainte Luce; one sample of $P$. sp. Ca1 Ranomafana (Ambatolahy, EU341067, Wollenberg et al. 2008; Fig. 4b); three samples of Rhombophryne sp. (formerly assigned to R. alluaudi) 

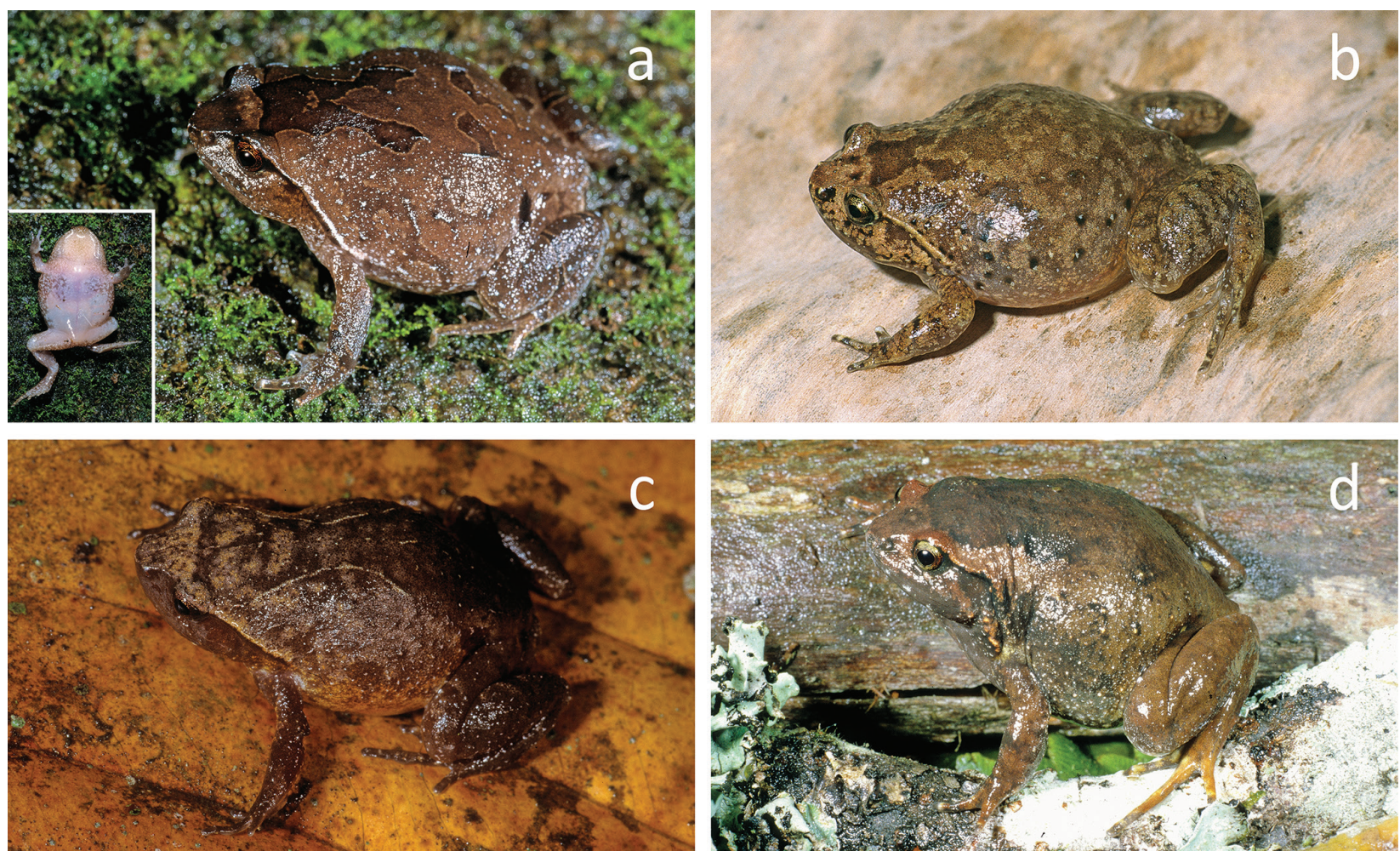

Figure 4. Individuals of (a) Plethodontohyla alluaudi in dorsolateral and (inset) ventral view (ZSM 89/2004, until now referred to as P. bipunctata; from Andohahela); (b) P. sp. Ca01 in dorsolateral view (ZCMV 555; from Ambatolahy); (c) P. brevipes in dorsolateral view (ZSM 649/2003; from Ranomafana); and (d) Rhombophryne sp. (formerly identified as $R$. alluaudi) in lateral view (ZFMK 52765 from Andasibe) (Photos by Frank Glaw and Miguel Vences).

from Torotorofotsy (ZCMV 968; EU341105, Wollenberg et al. 2008), Andasibe (ZSM 3/2002; AY594112, Andreone et al. 2005) and Tsararano (MRSN A2620; AY594105, Andreone et al. 2005); one sample of all nominal species of the genus Plethodontohyla (with the exception of P. notosticta for which we included sequences from individuals from two localities, one in the North and one in the South) were used in the molecular analyses (see Table 2 for more details). A homologous sequence of $R$. testudo, the type species of the genus Rhombophryne, was also included.

For the newly obtained samples, total genomic DNA was extracted using Proteinase K $(10 \mathrm{mg} / \mathrm{ml})$ digestion followed by a standard salt-extraction protocol (Bruford et al. 1992). We amplified one mitochondrial gene fragment (rrnL large ribosomal RNA or 16S rRNA gene) for all newly obtained tissues samples, and one nuclear gene fragment, the pro-opiomelanocortin (POMC) gene, for a subset of samples (see details in Table 2). Standard polymerase chain reactions were performed in a final volume of $25 \mu \mathrm{l}$ and using $0.75 \mu \mathrm{l}$ each of 10 pmol primer, $0.4 \mu \mathrm{l}$ of total dNTP $10 \mathrm{mM}$ (Promega), $0.1 \mu \mathrm{l}$ of $5 \mathrm{U} / \mathrm{ml}$ GoTaq (Promega), $5 \mu \mathrm{l}$ XX Green GoTaq Reaction Buffer (Promega) and $4 \mu \mathrm{l}$ of $\mathrm{MgCl}_{2} 25 \mathrm{mM}$ (Promega). To sequence a fragment of ca. $550 \mathrm{bp}$ of the 3 ' terminus of the mitochondrial large ribosomal RNA gene (16S), proven to be suitable for amphibian identification (Vences et al. 2005), we used the primers AC_16S_AR 5'CGCCTGTTTATCAAAAACAT3' and AC 16S_BR 5'CCGGTYTGAACTCAGATCAYGT3' modified from Kocher et al.
(1989) and Palumbi et al. (1991), using standard protocols. To sequence the POMC fragment, we used the primers POMC DRVF1 5'ATATGTCATGASCCAYTTYCGCTGGAA3' and POMC DRVR1 5'GGCRTTYTTGAAWAGAGTCATTAGWGG3' (Vieites et al. 2007) as in Vences et al. (2010). Successfully amplified fragments were purified and sequenced at Macrogen Inc., where labelled fragments were analysed on an ABI 3730XL automated DNA sequencer (Applied Biosystems).

Sequences were compared with GenBank sequences, and chromatographs were visually checked and edited, when necessary, using BIOEDIT 7.0.5.3 (Hall 1999). Gaps were included in the hypervariable regions of the $16 \mathrm{~S}$ to account for indels in the final alignment. All newly determined sequences have been deposited in GenBank (MG273701-MG273723; Table 2). Uncorrected pairwise distances ( $p$-distance transformed into percentage using the complete deletion option) amongst individuals of the same species and between ingroup analysed species were computed using MEGA 7.0.21 (Kumar et al. 2016).

Bayesian analyses were conducted in MRBAYES 3.2.2 (Ronquist et al. 2012). The GTR $+\mathrm{I}+\mathrm{G}$ model was determined by AIC in jModelTest2 (Darriba et al. 2012) as the best-fitting model of substitution. We performed two runs of 10 million generations (started on random trees) and four incrementally heated Markov chains (using default heating values), sampling the Markov chains at intervals of 1,000 generations. Stabilization and convergence of likelihood values were checked by visualizing the log 
Table 2. List of samples included for the molecular analyses with their respective localities, voucher and/or field number information, institutional catalogue number (where available) and GenBank accession numbers.

\begin{tabular}{|c|c|c|c|c|c|c|}
\hline Sample ID & Taxon & Locality & $\begin{array}{c}\text { Field } \\
\text { number }\end{array}$ & $\begin{array}{c}\text { Institutional catalogue } \\
\text { number }\end{array}$ & $\begin{array}{c}\text { Accession } \\
\text { nos. } 16 \mathrm{~S}\end{array}$ & $\begin{array}{l}\text { Accession } \\
\text { nos. POMC }\end{array}$ \\
\hline ACP1109 & Plethodontohyla laevis & Betampona & - & MRSN A6340 & $\begin{array}{c}\mathrm{HM} 364769 / \\
\text { FJ559294 }\end{array}$ & MG273712 \\
\hline ACP1901 & Plethodontohyla laevis & Betampona & ACZCV 0066 & ZSM 980/2013 & MG273701 & MG273713 \\
\hline ACP1108 & Plethodontohyla laevis & Betampona & - & MRSN A6189 & MG273702 & MG273714 \\
\hline ACP1107 & Plethodontohyla laevis & Betampona & - & MRSN A6181 & MG273703 & - \\
\hline ACP2196 & Plethodontohyla laevis & Betampona & ACZC 6262 & - & MG273704 & MG273715 \\
\hline ACP2214 & Plethodontohyla laevis & Betampona & ACZCV 0268 & - & MG273705 & MG273716 \\
\hline ACP2066 & Plethodontohyla laevis & Betampona & ACZC 5923 & - & MG273706 & MG273717 \\
\hline ACP1362 & Plethodontohyla laevis & Marovato & $\begin{array}{c}\text { PBZT-RJS } \\
2020\end{array}$ & MRSN A6674 & MG273707 & MG273718 \\
\hline ACP3171 & Plethodontohyla laevis & Analalava & FGZC 5239 & ZSM 189/2016 & MG273708 & - \\
\hline ACP1368 & Plethodontohyla laevis & Anivorano Est & $\begin{array}{c}\text { PBZT-RJS } \\
1830 \\
\end{array}$ & MRSN A6787 & MG273709 & MG273719 \\
\hline FGZC161 & Plethodontohyla alluaudi & Andohahela & FGZC 161 & ZSM 89/2004 & EU341068 & MG273720 \\
\hline ACP1056 & Plethodontohyla alluaudi & $\begin{array}{c}\text { Tsitongambarika } \\
\text { (Anosyenne Chain) }\end{array}$ & FAZC 15423 & - & MG273710 & MG273721 \\
\hline SE47 & Plethodontohyla alluaudi & Sainte Luce & - & - & MG273711 & - \\
\hline ZCMV555 & Plethodontohyla sp. CaO1 & Ambatolahy & ZCMV 555 & - & EU341067 & MG273722 \\
\hline ZCMV968 & Rhombophryne sp. & Torotorofotsy & ZCMV 968 & - & EU341105 & MG273723 \\
\hline na & Rhombophryne sp. & Tsararano & - & MRSN A2620 & AY594105 & - \\
\hline na & Rhombophryne sp. & Andasibe & - & ZSM 3/2002 & AY594112 & - \\
\hline na & Plethodontohyla ocellata & Ambohitsara & ZCMV 88 & UADBA uncatalogued & EU341062 & - \\
\hline na & Plethodontohyla brevipes & Maharira & ZCMV 270 & - & EU341063 & - \\
\hline na & Plethodontohyla fonetana & Bemaraha & FGZC 917 & ZSM 123/2006 & EU341058 & - \\
\hline na & Plethodontohyla guentheri & Marojejy & FGZC 2814 & ZSM 61/2005 & EU341059 & - \\
\hline na & Plethodontohyla inguinalis & Vohiparara & - & ZMA 20223 & EU341057 & - \\
\hline na & Plethodontohyla mihanika & Ranomafana & ZCMV 308 & UADBA uncatalogued & EU341056 & - \\
\hline na & Plethodontohyla notosticta & Nosy Mangabe & ZCMV 2106 & - & EU341061 & - \\
\hline na & Plethodontohyla notosticta & Manombo & ZCMV 471 & - & EU341060 & - \\
\hline na & Plethodontohyla bipunctata & Tolagnaro & RAX 10726 & - & KM509181 & - \\
\hline na & Plethodontohyla tuberata & Manjakatompo & - & ZSM 375/2000 & EU341064 & - \\
\hline na & Rhombophryne testudo & Nosy Be, Lokobe & - & ZSM 474/2000 & KC180070 & - \\
\hline na & Scaphiophryne marmorata & Andasibe & - & ZSM 4/2002 & AY834191 & - \\
\hline
\end{tabular}

likelihoods associated with the posterior distribution of trees in the software TRACER 1.5 (Rambaut and Drummond 2007), and occurred after about 3-3.5 million generations. The first four million generations were conservatively discarded, and six million trees were retained post burn-in and summed to generate the majority rule consensus tree (Fig. 5a). The purpose of the presented phylogenetic analyses is: 1) to show that the four analysed populations of $P$. laevis form a monophyletic group; 2) to show the closest phylogenetic relationship of this species to $P$. alluaudi in its new definition and $P$. sp. $\mathrm{Ca} 01$ (which might prove to be conspecific with $P$. alluaudi); and 3) to show that the specimens formely assigned to 'Rhombophryne alluaudi' (from Torotorofotsy, Andasibe, and Tsararano) do not belong to the genus Plethodontohyla, rather than provide a phylogenetic hypothesis of the phylogenetic relationships of Plethodontohyla species and support for the genus monophyly.

Alternative alleles of the analysed POMC gene fragment were inferred using the PHASE algorithm (Stephens et al. 2001) implemented in the software DNASP
5.10.3 (Librado and Rozas 2009). Haplotype network reconstruction of POMC phased sequences (Fig. 5b) was performed using the software TCS 1.21 (Clement et al. 2000). This software employs the method of Templeton et al. (1992) and calculates the number of mutational steps by which pairwise haplotypes differ, computing the probability of parsimony for pairwise differences until the probability exceeds 0.95 (no manual adjustment of threshold was necessary). The minimum number of mutational steps required to connect the two networks obtained using the parsimony method of Templeton et al. (1992) was identified using the 'fix connection limit' option as implemented in TCS.

\section{Bioacoustic analyses}

Vocalizations of $P$. laevis were recorded in the field with a Marantz PMD 660 digital recorder, accessorized with a semi-directional microphone. Calls were successively analysed with the acoustic software ADOBE AUDITION 3.0. Definition of variables and terminology in call descriptions follow Rosa and Andreone (2010), Rosa et 


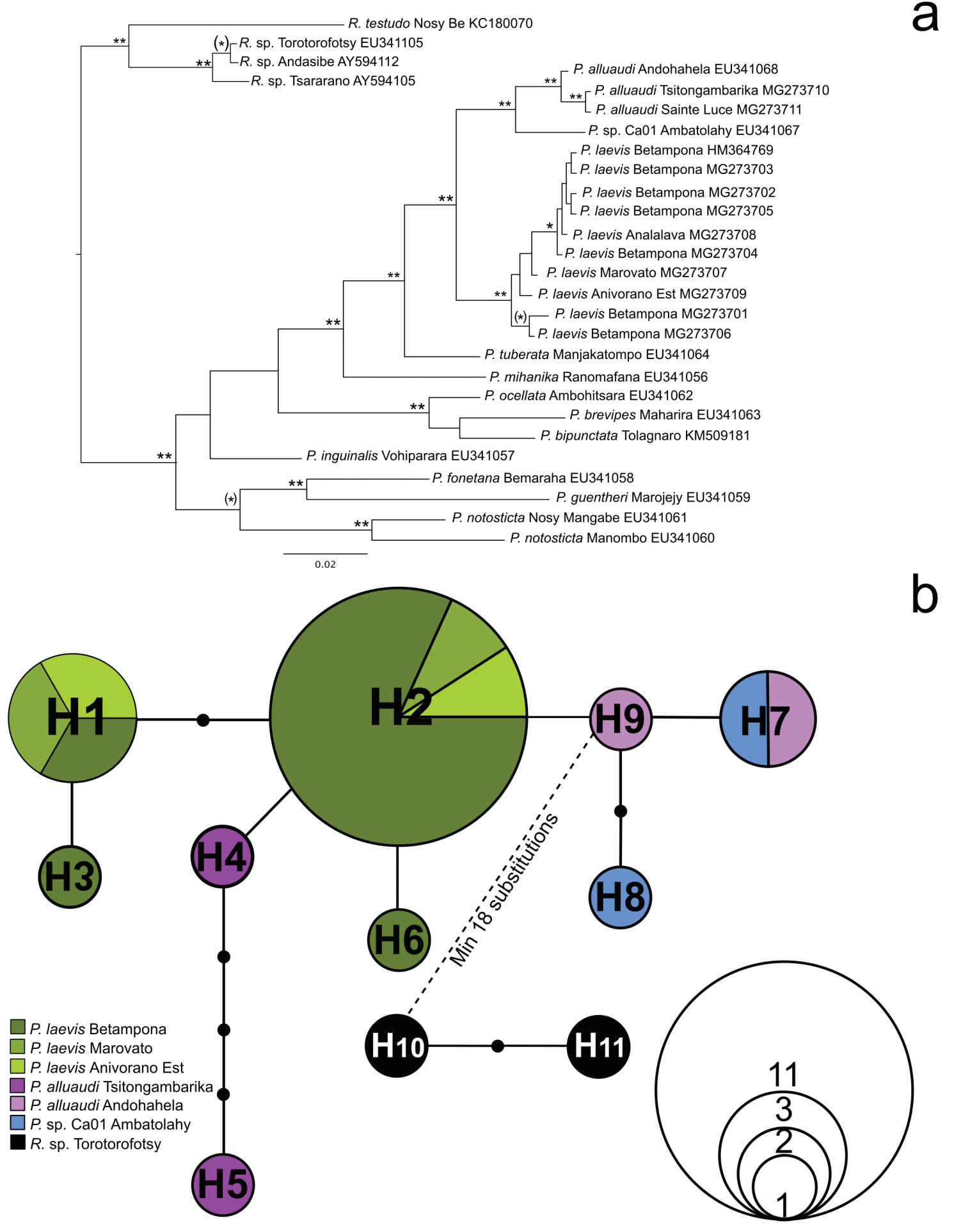

Figure 5. a) Bayesian inference tree based on 529 bp of the mitochondrial 16S. Asterisks denote Bayesian posterior probabilities values: one asterisk enclosed in parentheses, $\geq 90 \%$; one asterisk, $\geq 98 \%$; two asterisks, $\geq 99-100 \%$. b) Haplotype network reconstruction for the phased alleles of the nuclear POMC gene fragment in P. laevis from Betampona, Marovato and Anivorano Est, P. alluaudi from Tsitongambarika and Andohahela, P. sp. Ca01 from Ambatolahy and Rhombophryne sp. from Torotorofotsy.

al. (2010, 2011) and Köhler et al. (2017), and calls are compared to described Plethodontohyla vocalizations available in the literature (see Table 3). Recordings were re-sampled at $44,100 \mathrm{~Hz}$ and 16 bit resolution in mono and with the 'Waveform' extension. Frequency informa- tion was obtained through Fast Fourier Transformation (FFT, width 1024 points); the audiospectrogram was obtained with a Hanning window function resolution of 256 bands. 
Table 3. Comparative measurements from advertisement calls of Plethodontohyla species.

\begin{tabular}{|c|c|c|c|c|c|c|c|c|}
\hline Species & $\begin{array}{l}\text { Temp. } \\
\left({ }^{\circ} \mathrm{C}\right)\end{array}$ & $\begin{array}{c}\text { Series } \\
\text { of } \\
\text { notes }\end{array}$ & $\begin{array}{l}\text { Note duration } \\
(\mathrm{ms})\end{array}$ & $\begin{array}{l}\text { Duration of inter- } \\
\text { note intervals (s) }\end{array}$ & $\begin{array}{l}\text { Note } \\
\text { repetition } \\
\text { rate }(n / s)\end{array}$ & $\begin{array}{c}\text { Dominant } \\
\text { frequency } \\
(\mathrm{Hz})\end{array}$ & $\begin{array}{c}\text { Visible } \\
\text { harmonics }\end{array}$ & Reference \\
\hline P. laevis & 21 & 1 & $\begin{array}{c}391-422 \\
(407 \pm 12.7, n=4)\end{array}$ & $47(n=1)$ & 0.04 & 1820-2530 & 11 & this study \\
\hline P. alluaudi* & 24 & 1 & $\frac{320-560}{(478 \pm 109, n=4)}$ & unknown & unknown & $1400-2100$ & 0 & this study \\
\hline P. inguinalis & 21 & 1 & $\frac{133-191}{(148 \pm 18, n=10)}$ & $\begin{array}{c}0.85-1.15 \\
(1 \pm 0.085, n=10)\end{array}$ & 0.9 & $800-1300$ & 1 & Vallan et al. (2005) \\
\hline P. mihanika & 24.5 & 1 & $\frac{150-172}{(159 \pm 6, n=12)}$ & $\frac{4-7.2}{(5.3 \pm 1, n=11)}$ & 0.18 & 1900-2200 & 4 & Vences et al. (2003) \\
\hline P. notosticta & $\begin{array}{c}\text { unknown } \\
19\end{array}$ & $\begin{array}{l}1 \\
1\end{array}$ & \begin{tabular}{|c|}
$280-340$ \\
$365-412$ \\
$(391 \pm 13.3, n=15)$ \\
\end{tabular} & $\begin{array}{c}2 \\
3.9-5.4 \\
(3.7 \pm 0.74, n=14)\end{array}$ & $\begin{array}{l}0.43 \\
0.26\end{array}$ & $\frac{1000}{930-1330}$ & $\begin{array}{c}\text { unknown } \\
9\end{array}$ & $\begin{array}{c}\text { Glaw and Vences (1992) } \\
\text { Rosa et al. (2011); } \\
\text { this study }\end{array}$ \\
\hline
\end{tabular}

* due to the low quality of the available recordings not all the parameters were possible to obtain.

Temporal measurements are provided as range, followed by mean, standard deviation and number of analysed units (n). We measured air temperature (to the nearest $1{ }^{\circ} \mathrm{C}$ ) with digital devices at close distance to calling frogs (i.e. temperature information refers to air temperature at the time of recording, not body temperature of the calling specimen). The number of recordings did not allow for temperature corrections.

\section{Results and discussion}

We here present evidence that (1) Dyscophus alluaudi and Phrynocara laeve are both members of the genus Plethodontohyla; (2) Plethodontohyla laevis tsianovohensis is more similar to D. alluaudi than Ph. laevis; (3) the osteology and morphology of the holotypes of $D y$ scophus alluaudi and Phrynocara laeve indicate that they are not conspecific; (4) the species of Rhombophryne currently called $R$. 'alluaudi' from the Andasibe region has no affinity with that species; (5) populations of $P$. sp. Ca3 from Betampona are conspecific with Phrynocara laeve; and (6) populations of a species of Plethodontohyla from southern Madagascar, until now referred to as ' $P$. bipunctata' (ZSM 89/2004) are conspecific with Dyscophus alluaudi. Based on these findings, we resurrect and re-describe Plethodontohyla laevis, we transfer Dyscophus alluaudi to the genus Plethodontohyla and re-describe it.

\section{Identity of the holotypes of Dyscophus alluaudi, Phryno- cara laeve and Plethodontohyla laevis tsianovohensis}

We examined the type material of Dyscophus alluaudi, which is currently assigned to the genus Rhombophryne, and its junior synonyms Phrynocara laeve and Plethodontohyla laevis tsianovohensis (depicted in Fig. 2). As we have intimated previously (Scherz et al. 2016a, b), an increasing body of evidence suggests that the name $D$. alluaudi is misapplied. Our investigation resulted in strong evidence for taxonomic placement of the respective names:

(1) The holotype of Dyscophus alluaudi, MNHN 1901.235 (Fig. 2c, d), is an adult ovigerous female specimen measuring $47.4 \mathrm{~mm}$ in SVL (for all other measurements see
Table 1). It has knob-like terminal phalanges, an unossified pubis, tri-radiate prechoanal vomer with the lateral ramus situated at the midpoint, a strongly descending lateral flange of the frontoparietal, a short maxillary facial process, frontoparietals not extending beyond the level of the neopalatine and a well-developed transverse dorsal ridge on the frontoparietal (Fig. 6, see Suppl. material 1). The pectoral girdle has highly reduced clavicles (remaining just as short thin bony elements near the glenoid socket; indicated by arrows in Fig. 6) and a facet near the middle of the anterior edge of the coracoid. The pectoral girdle has been exposed on the specimen, and a thin cartilaginous extension of the procoracoid runs from the anterior glenoid socket to the facet on the leading edge of the coracoid, and then broadens and runs along it to the omosternum (intact only on the left side); the bony remnants of the clavicles are barely discernable through the dissecting microscope, as they are transparent and very thin. A similar condition to that seen in Dyscophus alluaudi was described for the type specimen of Mantipus angeli by Guibé (1974; confirmed by M.D. Scherz, personal observation), which is a synonym of Plethodontohyla tuberata (Peters, 1883). This state was unknown to Scherz et al. (2016a), suggesting the diagnostic value of the 'absence of clavicles' paired with absence of nasal-frontoparietal contact for Plethodontohyla recognition must be refined to include also these reduced lateral elements. The configuration is nevertheless clearly different from Rhombophryne, including the reduced clavicles of species like R. mangabensis (M.D. Scherz et al. unpublished data).

(2) The holotype of Phrynocara laeve, SMF 4286 (Fig. 2a, b), is probably also an adult female (with developing eggs), measuring $38.1 \mathrm{~mm}$ in SVL (for all other measurements see Table 1). It lacks clavicles, has knob-like terminal phalanges, an unossified pubis, a tri-radiate prechoanal vomer with the lateral ramus displaced anteriorly, lateral flange of frontoparietal not descending strongly, a short maxillary facial process, frontoparietals extending beyond the level of the neopalatine and a well-developed if discontinuous transverse dorsal ridge on the frontoparietal (Fig. 6, Suppl. material 2). It differs strongly from MNHN 1901.235 in its smaller size (SVL 38.1 vs. 47.4 $\mathrm{mm}$ ), much narrower head (HW/HL 1.56 vs. 1.85), longer 

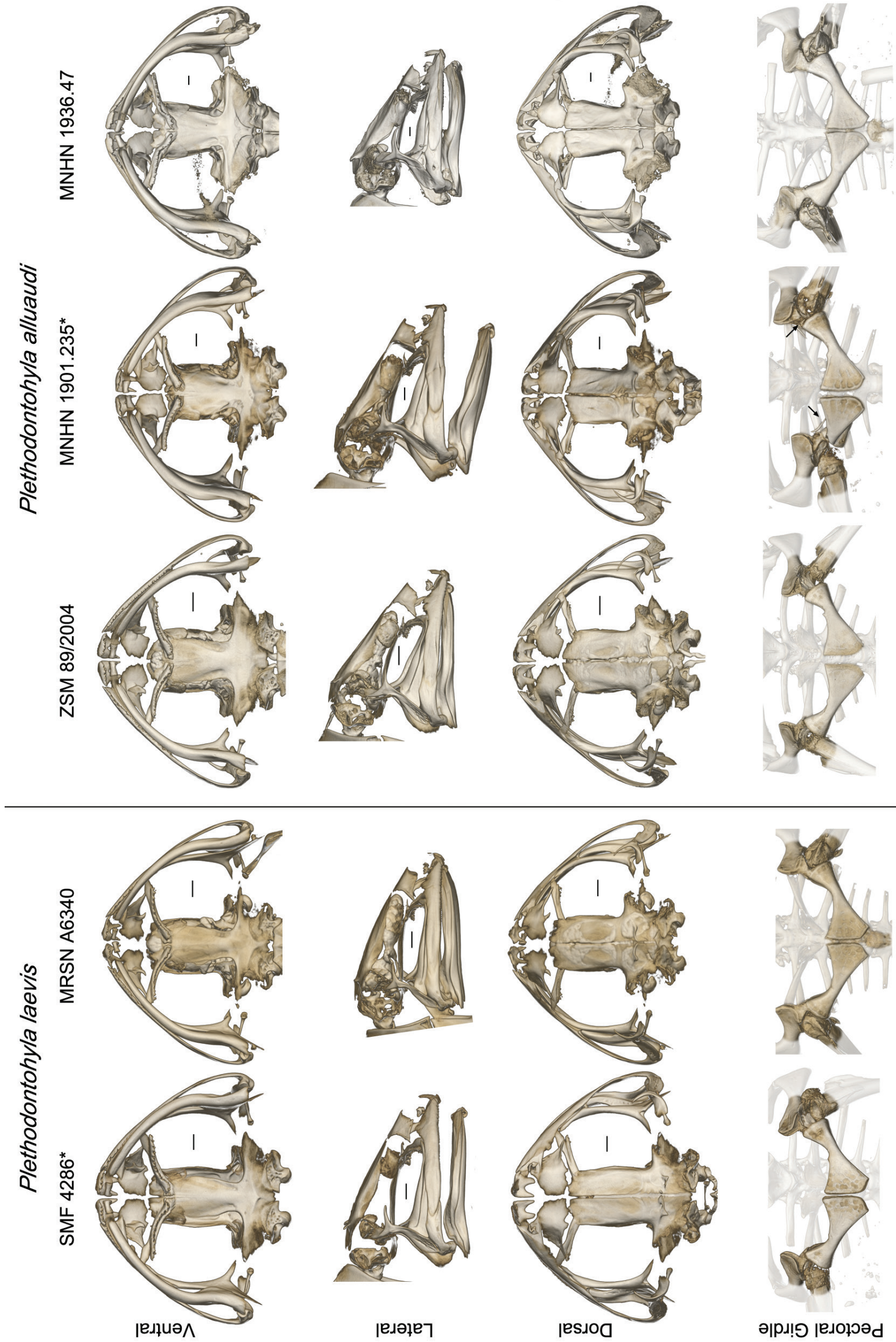

Figure 6. Skull and pectoral girdle morphology of Plethodontohyla alluaudi and P. laevis. Asterisks indicate the holotypes of each species. Arrows on the pectoral girdle of $P$. alluaudi MNHN 1901.235 indicate the clavicles. Scale bars indicate $1 \mathrm{~mm}$. 
relative forelimb length (FORL/SVL 0.56 vs. 0.47), longer relative hindlimb length (HIL/SVL 1.43 vs. 1.25), the absence of large dark inguinal spots ( $v s$. presence), lateral ramus of the prechoanal vomer displaced anteriorly ( $v s$. central), frontoparietals exceeding the level of the neopalatine (vs. not exceeding the neopalatine) and the weakly descending lateral flange of the frontoparietal (vs. strongly). The pectoral girdle is similar to MNHN 1901.235, but has also been damaged, obscuring the state - it nevertheless lacks the ossified clavicles of that specimen. We therefore conclude that it is not a synonym of $D$. alluaudi, but instead a valid species in need of resurrection. Its osteology also suggests that it is a member of the genus Plethodontohyla, on the basis of the absence of clavicles and lack of nasal-frontoparietal contact.

(3) The type specimen of Plethodontohyla laevis tsianovohensis, MNHN 1936.47 (Fig. 2e, f), is also an adult, ovigerous female measuring $58.0 \mathrm{~mm}$ in SVL (for all other measurements see Table 1). It lacks clavicles, but has the same cartilaginous pectoral arrangement as the holotype of D. alluaudi, but on the left side it has been damaged so that a second pectoral fenestra is formed medial to the anterior facet of the coracoid, where it ought not to be. In addition, it has knob-like terminal phalanges, an ossified pubis, an almost crescentic prechoanal vomer with a weak lateral ramus, a strongly descending lateral flange of the frontoparietal, a long maxillary facial process, frontoparietals not extending beyond the level of the neopalatine and a well-developed transverse dorsal ridge on the frontoparietal (Fig. 6, Suppl. material 3). Its affiliations are not quite clear; it is larger in size than either D. alluaudi or Ph. laeve (SVL 58.0 vs. 47.4 and $38.1 \mathrm{~mm}$, respectively), its arms are longer than those of $D$. alluaudi but shorter than those of Ph. laeve (FORL/ SVL 0.53 vs. 0.47 and 0.56 , respectively), it has longer legs than both (HIL/SVL 1.47 vs. 1.25 and 1.43, respectively), its tympanum is broader than both (TD/ED 0.58 vs. 0.53 and 0.40 , respectively), and its osteology shares some elements with either species and differs from both in others (e.g. the length of the facial process). Overall, the skeleton and external morphology more closely resembles that of MNHN 1901.235, and we therefore tentatively conclude that $P . l$. tsianovohensis should be left in the synonymy of $D$. alluaudi. However, we emphasise that the D. alluaudi and P. $l$. tsianovohensis type specimens do not agree in all aspects of their morphology, and their type localities are separated by at least $300 \mathrm{~km}$ (Fig. 1), so this taxon may eventually be recognized as a valid, species-level name (possibly it may represent $P$. sp. Ca01, whose osteology has not been studied here, but see below). It must therefore be re-visited in future treatments of the taxonomy of the P. alluaudi complex. In any case, it is the most junior of the available names, and its identity can remain unresolved for the time being.

\section{Identity of recently collected specimens}

As a next step, we analysed the osteology and morphology of three more recently collected specimens: (1) ZSM 3/2002, a specimen from Andasibe of the species currently referred to as 'Rhombophryne alluaudi' following
Blommers-Schlösser (1975) and Glaw and Vences (1992); (2) MRSN A6340, a specimen of a species of Plethodontohyla collected from near the potential type locality of Phrynocara laeve that agrees strongly with the original description of that species; and (3) ZSM 89/2004, a specimen of a species of Plethodontohyla collected in Andohahela, near to the type locality of Dyscophus alluaudi.

(1) ZSM $3 / 2002$ is genetically a member of the genus Rhombophryne (Figs 4d, 5a). Osteologically, it resembles other published and unpublished Rhombophryne skeletons (Scherz et al. 2014, 2015a, b, 2016a, b, 2017, unpublished data) and it differs unambiguously from the holotype of Dyscophus alluaudi: it has fully developed clavicles (vs. rudimentary clavicles present in the holotype of $D$. alluau$d i)$, two independent dorsal processes on the frontoparietal (rather than a more or less continuous ridge) and a fused presacral VIII and sacrum (Suppl. material 4). Additionally, it lacks inguinal spots and any trace of the pattern originally described for Dyscophus alluaudi. Thus, it is clear that the taxon Dyscophus alluaudi is currently misapplied. Based on its molecular phylogenetic identity (Table 2; Fig. 5a), as well as the presence of curved clavicles and knobbed terminal phalanges, this species is a member of the genus Rhombophryne. It does not match any other described species of Rhombophryne, and will therefore be described in a forthcoming revision of that genus.

(2) MRSN A6340 is a specimen of Plethodontohyla collected at Betampona and genetically similar to other specimens collected at Marovato, Anivorano Est and Analalava-Foulpointe (Table 2; Fig. 5). It is an adult male (collected when calling), measuring $33.0 \mathrm{~mm}$ in SVL (for all other measurements see Table 1). It lacks clavicles, has knob-like terminal phalanges, a mostly unossified pubis, a tri-radiate vomer with a lateral ramus displaced anteriorly, lateral flange of frontoparietal not descending strongly, a moderately short maxillary facial process, frontoparietals extending beyond the level of the neopalatine and a well-developed transverse dorsal ridge on the frontoparietal (Fig. 6, Suppl. material 5). In all of these respects, it strongly resembles the osteology of the holotype of Phrynocara laeve. Its external morphology also resembles that species, though it differs somewhat in ratios (but note the variability of measurements shown in Table 1). It differs clearly from Dyscophus alluaudi and Pl. laevis tsianovohensis on the same grounds given above from $P h$. laeve, i.e. the absence of large dark inguinal spots (vs. presence in D. alluaudi), lateral ramus of prechoanal vomer displaced anteriorly (vs. central), frontoparietal exceeding the level of the neopalatine (vs. not exceeding the neopalatine) and the weakly descending lateral flange of the frontoparietal ( $v s$. strongly). We therefore conclude that this species is assignable to Plethodontohyla laevis, distinct from Plethodontohyla alluaudi, and we resurrect and re-describe it below based on data from the holotype and our new material.

(3) ZSM 89/2004 is a specimen collected in Andohahela and genetically belonging to the genus Plethodontohyla (Table 2; Figs 4a, 5). This specimen is molecularly 
similar to other specimens collected at Tsitongambarika and Sainte Luce and moderately similar to the sequence of a specimen collected at Ambatolahy (Fig. 5). ZSM $89 / 2004$ has close genetic affinities to the specimens that we here confer to $P$. alluaudi, representing a closely related clade (see Fig. 5a). Osteologically, it differs from the holotype of Phrynocara laeve (and other specimens conferred to that taxon) in the following respects: lateral ramus of prechoanal vomer central (vs. displaced anteriorly), and lateral flange of frontoparietal descending strongly ( $v s$. not descending strongly). Its coracoids show distinct facets for the attachment of cartilage, more strongly developed than in P. laevis. By comparison, it differs from Dyscophus alluaudi in the narrower skull, frontoparietals exceeding the level of the neopalatine, absence of clavicle remnants and the proportions of some skull elements (compare the skulls in Fig. 6, Suppl. material 6). However, we hypothesise that these differences between this specimen and the holotype of Dyscophus alluaudi are due to the considerable difference in body size (SVL 29.1 vs. $47.4 \mathrm{~mm}$ ) and that the proportions of the skull and its ossification are correlates of age and size. The differences to Phrynocara laeve appear more substantial, despite the similarity in size. Both ZSM 89/2004 and UADBA-A 27994 (FGZC 160) possess inguinal spots and agree in external morphology with Dyscophus alluaudi. We therefore attribute these populations from southern Madagascar to Plethodontohyla alluaudi, and we re-describe this species below.

\section{Remarks on the identity of $P$. sp. Ca01 and $P$. brevipes}

Fig. 4b, c

We note that the specimen representing $P$. sp. Ca01 (ZCMV 555) from Ambatolahy in eastern Madagascar $\left(21^{\circ} 14^{\prime} 37.92^{\prime \prime} \mathrm{S}, 047^{\circ} 25^{\prime} 34.38^{\prime \prime} \mathrm{E}\right)$ is genetically very similar to the samples attributed to $P$. alluaudi and phylogenetically represents the sister taxon of the specimens here attributed to $P$. alluaudi. A picture of a specimen of $P$. sp. Ca01, ZCMV 555 (or 556, a second not yet sequenced individual) was depicted as Plethodontohyla brevipes on page 125 of Glaw and Vences (2007b) and in Fig. 1 of Scherz et al. (2016a). Two additional specimens belonging to this taxon are currently present in the ZSM collection: ZSM 855/2006 and ZSM 856/2006. Elements of the overall appearance of specimens ZCMV 555 (based on the photograph) and ZSM 855/2006 and ZSM 856/2006 disagree with the description of that species, most notably by the presence of a distinct marking over the back of the head (originally described as 'uniform dark brown above'). In contrast, they bear a remarkable resemblance to $P$. alluaudi and $P$. laevis. These specimens may therefore be closely related to the holotype of P. laevis tsianovohensis, which is from an area comparatively near to Ambatolahy. Nevertheless, the taxonomic status of $P$. sp. $\mathrm{Ca} 01$, and also the relationships of Plethodontohyla brevipes based on its holotype (BMNH 1947.2.10.42), clearly need to be revised. This is however beyond the scope of the current study, and must be conducted in the context of a larger revision of the genus. In the diagnoses against $P$. brevipes presented for the following re-descriptions, we included only measurements from specimens that resemble the original description in having uniformly brown dorsal colouration and slightly granular dorsal skin.

\section{Molecular analyses}

Among representatives of the genus Plethodontohyla, the mean uncorrected $p$-distance (for the $16 \mathrm{~S}$ fragment) of $P$. laevis varies between $5.5 \%$ (comparison with $P$. sp. $\mathrm{Ca} 01$ which may be conspecific with $P$. alluaudi) and $11.5 \%$ (comparison with $P$. guentheri and with $P$. brevipes). Our data also reveal some genetic differentiation between the four known populations of $P$. laevis, with an intraspecific mean uncorrected $p$-distance of $1.1 \%$ (Table $4)$. For other intraspecific comparisons and comparisons with other Plethodontohyla species see Table 4.

The two Bayesian analyses resulted in largely identical trees, with only minor changes in posterior probability values, and showed that $P$. laevis from the four analysed localities forms a robust monophyletic group (posterior probability [PP] 0.99). Our analyses recovered a moderately supported sister relationship (PP 0.94) for P. laevis and the clade composed of $P$. alluaudi in its new definition and $P$. sp. $\mathrm{Ca} 01$ from Ambatolahy (Fig. 5a). The mean uncorrected $p$-distance of $P$. sp. $\mathrm{Ca} 01$ and $P$. alluaudi is $2.9 \%$ and these taxa might indeed represent two populations of the same species. Similarly, the three specimens from Torotorofotsy, Andasibe and Tsararano belonging to the genus Rhombophryne apparently are the same taxon (mean uncorrected $p$-distance $0.7 \%$; PP 1.0 ), although a more extensive phylogenetic analysis of Rhombophryne will be required to further confirm this result.

The haplotype network reconstruction of the nuclear POMC gene (Fig. 5b) shows no haplotype sharing between Plethodontohyla laevis (from Betampona, Marovato and Anivorano Est) and $P$. alluaudi. Wide haplotype sharing is observed between the three analysed populations of $P$. laevis used in this analysis, with at least two haplotypes (haplotype $\mathrm{H} 1$ and H2; Fig. 5b) found in all three populations; and haplotype sharing is observed also between $P$. alluaudi from Andohahela and $P$. sp. Ca01 from Ambatolahy (haplotype H7; Fig. 5b).

The analysis of haplotype network reconstruction fails to recover a single statistically significant haplotype network for the analysed dataset that comprises representative samples of $P$. laevis from three localities, $P$. alluaudi from two localities, $P$. sp. Ca01 and the Rhombophryne species from Torotorofotsy, and a minimum of 18 substitutions are required to join these two haplotype networks (see Fig. $5 b$ for details).

\section{Plethodontohyla laevis (Boettger, 1913), bona species}

Figs 2a, b, 3, 6-8, Suppl. materials 2, 5

Remarks. This species has been referred to as Plethodontohyla sp. 3 'Betampona' by Vieites et al. (2009), Pletho- 
Table 4. Estimates of evolutionary divergence over sequence pairs within- (bold) and between-species for the analysed 16S rRNA mitochondrial gene fragment. The number of base differences per site averaged over all sequence pairs within and between groups are shown. The analysis involved 28 nucleotide sequences. All positions containing gaps and missing data were eliminated. There were a total of 300 positions in the final dataset. Evolutionary analyses were conducted in MEGA7 (Kumar et al. 2016). The presence of $\mathrm{n} / \mathrm{c}$ (not computed) in the results denotes cases in which it was not possible to estimate evolutionary distances. ' $R$. sp.' refers to the undescribed Rhombophryne species formerly assigned to $R$. alluaudi.

\begin{tabular}{|c|c|c|c|c|c|c|c|c|c|c|c|c|c|c|}
\hline & \begin{tabular}{c|}
$P$. \\
alluaudi
\end{tabular} & $\begin{array}{l}\text { P. sp. } \\
\mathrm{CaO1}\end{array}$ & P. laevis & R. sp. & $\begin{array}{c}P \\
\text { ocellata }\end{array}$ & \begin{tabular}{c|}
$P$. \\
brevipes
\end{tabular} & $\begin{array}{c}P . \\
\text { fonetana }\end{array}$ & \begin{tabular}{c|}
$P$. \\
guentheri
\end{tabular} & $\begin{array}{c}P . \\
\text { inguinalis }\end{array}$ & $\begin{array}{c}P . \\
\text { mihanika }\end{array}$ & \begin{tabular}{c|}
$P$. \\
notosticta
\end{tabular} & $\begin{array}{c}P . \\
\text { bipunctata }\end{array}$ & $\begin{array}{c}P . \\
\text { tuberata }\end{array}$ & $\begin{array}{c}R . \\
\text { testudo }\end{array}$ \\
\hline P. alluaudi & $0.7 \%$ & & & & & & & & & & & & & \\
\hline P. sp. $\mathrm{CaO} 1$ & $2.9 \%$ & $n / c$ & & & & & & & & & & & & \\
\hline P. laevis & $5.8 \%$ & $5.5 \%$ & $1.1 \%$ & & & & & & & & & & & \\
\hline R. sp. & $12.4 \%$ & $12.1 \%$ & $12.6 \%$ & $0.7 \%$ & & & & & & & & & & \\
\hline P. ocellata & $9.0 \%$ & $9.3 \%$ & $9.9 \%$ & $9.4 \%$ & $\mathrm{n} / \mathrm{c}$ & & & & & & & & & \\
\hline P. brevipes & $10.4 \%$ & $10.7 \%$ & $11.5 \%$ & $9.4 \%$ & $5.0 \%$ & $\mathrm{n} / \mathrm{c}$ & & & & & & & & \\
\hline P. fonetana & $10.4 \%$ & $10.0 \%$ & $9.9 \%$ & $9.0 \%$ & $9.3 \%$ & $11.3 \%$ & $n / c$ & & & & & & & \\
\hline P. guentheri & $11.1 \%$ & $10.0 \%$ & $11.5 \%$ & $10.3 \%$ & $11.0 \%$ & $11.7 \%$ & $7.7 \%$ & $\mathrm{n} / \mathrm{c}$ & & & & & & \\
\hline P. inguinalis & $9.9 \%$ & $9.3 \%$ & $9.6 \%$ & $8.1 \%$ & $7.0 \%$ & $8.7 \%$ & $7.3 \%$ & $8.3 \%$ & $\mathrm{n} / \mathrm{c}$ & & & & & \\
\hline P. mihanika & $9.3 \%$ & $8.3 \%$ & $7.0 \%$ & $10.4 \%$ & $9.7 \%$ & $11.7 \%$ & $7.7 \%$ & $10.7 \%$ & $9.0 \%$ & $\mathrm{n} / \mathrm{c}$ & & & & \\
\hline P. notosticta & $11.6 \%$ & $10.8 \%$ & $10.4 \%$ & $10.6 \%$ & $10.5 \%$ & $10.5 \%$ & $9.8 \%$ & $10.3 \%$ & $9.5 \%$ & $9.7 \%$ & $0.6 \%$ & & & \\
\hline P. bipunctata & $9.4 \%$ & $9.3 \%$ & $9.5 \%$ & $9.8 \%$ & $2.3 \%$ & $3.70 \%$ & $9.7 \%$ & $10.7 \%$ & $6.7 \%$ & $10.0 \%$ & $9.5 \%$ & $\mathrm{n} / \mathrm{c}$ & & \\
\hline P. tuberata & $5.6 \%$ & $5.7 \%$ & $7.2 \%$ & $10.8 \%$ & $8.7 \%$ & $10.0 \%$ & $9.7 \%$ & $10.0 \%$ & $8.7 \%$ & $8.3 \%$ & $10.7 \%$ & $9.0 \%$ & $\mathrm{n} / \mathrm{c}$ & \\
\hline R. testudo & $12.8 \%$ & $14.0 \%$ & $14.2 \%$ & $8.6 \%$ & $11.3 \%$ & $11.70 \%$ & $13.0 \%$ & $13.0 \%$ & $9.3 \%$ & $12.3 \%$ & $12.3 \%$ & $10.3 \%$ & $11.3 \%$ & $\mathrm{n} / \mathrm{c}$ \\
\hline
\end{tabular}

dontohyla sp. aff. brevipes [Ca FJ559294] by Rosa et al. (2011, 2012) and Plethodontohyla sp. Ca03 Betampona by Scherz et al. (2016a). Blommers-Schlösser (1975) referred to a male specimen from 'near Tampoketsa d'Ankazobe’ (approx. 18¹9’05.5’S, 04706’42.8’'E , Fig. 1) as $P$. laevis. This locality from the central highlands is indeed closer to the distribution range of $P$. laevis than to $P$. alluaudi (as refined here), but we consider this record uncertain until the specimen (ZMA 6688) has been examined.

Resurrection of Plethodontohyla laevis. As we have shown above, several osteological and morphological characters exist to distinguish the holotypes of Dyscophus alluaudi and Phrynocara laeve. Osteological characters suggest that both taxa are members of the genus Plethodontohyla. Specimens recently collected in Betampona Special Reserve closely match the morphology, osteology and appearance of the holotype of Phrynocara laeve. A village named Sakana (in the Vavatenina commune, Toamasina Province) was located by using Google Earth roughly $70 \mathrm{~km}$ North of Betampona $\left(17^{\circ} 18^{\prime} 00.00^{\prime \prime} \mathrm{S}\right.$, $049^{\circ} 01^{\prime} 59.99^{\prime \prime} \mathrm{E}$ ), and we suspect that this may have been the forest to which Boettger was referring in the original description (Boettger 1913). The newly collected material in Betampona, Marovato, Anivorano Est and Analalava-Foulpointe is genetically and morphologically relatively uniform and it is distinct both from Plethodontohyla alluaudi (in its new definition), and from all other nominal Plethodontohyla species. We therefore resurrect Plethodontohyla laevis (Boettger, 1913) from the synonymy of $P$. alluaudi and we provide a re-description of it based on the re-examination of its holotype (including its osteology via micro-CT scanning), and examination of additional, newly collected material.
Holotype. SMF 4286, an adult female collected by A. Voeltzkow in 1905 in Sakana, East Madagascar.

Referred material. Adult male (ethanol-fixed, DNA sequenced and included in Rosa et al. 2012: Accession number HM364769) MRSN A6340 (FAZC 13902), collected by G.M. Rosa and J. Noël on 18 November 2007 at Betampona Nature Reserve, campsite Maintimbato $\left(17^{\circ} 533^{\prime} 35.5^{\prime \prime} \mathrm{S}, 049^{\circ} 13^{\prime} 41.3\right.$ ”'E, $283 \mathrm{~m}$ a.s.1.), Toamasina Province, eastern Madagascar. MRSN A6189 (FAZC 13643), adult female (ethanol-fixed and DNA sequenced), collected by G.M. Rosa and J. Noël on 21 February 2007 at Betampona Reserve campsite Maintimbato (1753'36.9'S, 049¹3'37.2'E, $295 \mathrm{~m}$ a.s.1.); MRSN A6181 (FAZC 13494), adult female (ethanol-fixed and DNA sequenced), collected by G.M. Rosa and J. Noël on 4 February 2007 at Betampona Reserve, Piste Principal $\left(17^{\circ} 55^{\prime} 40.5^{\prime}\right.$ 'S, 049 $12^{\prime} 07.4^{\prime \prime} \mathrm{E}, 355 \mathrm{~m}$ a.s.1.); ZSM 980/2013 (ACZCV 0066), adult male (ethanol-fixed and DNA sequenced), collected by A. Crottini, D. Salvi, E. Scanarini and J.H. Velo on the morning of 9 November 2013 at Betampona Nature Reserve, campsite Sahaïndrana $\left(17^{\circ} 53^{\prime} 55.50^{\prime \prime} \mathrm{S}, 049^{\circ} 12^{\prime} 02.4^{\prime \prime}\right.$, $327 \mathrm{~m}$ a.s.1.); UADBA uncatalogued (ACZCV 0268), adult unsexed (ethanol-fixed and DNA sequenced), collected by A. Crottini, D. Salvi, E. Scanarini, F. Andreone, S. Faravelli, J. Noël and Georges on the evening of 20 November 2013 at Betampona Nature Reserve, campsite Sahabefoza (1754'54.82”S, 049¹2'32.31'E, 349 m a.s.1.); MRSN A6674 (PBZT-RJS 2020), adult female (ethanol-fixed and DNA sequenced), collected by J.E. Randrianirina on 17 October 2008 at Marovato (1841'09.60”S, 048³6’19.80’E, 692 m a.s.1.); MRSN A6787 (PBZT-RJS 1830), adult male (ethanol-fixed and DNA sequenced), collected by J.E. Randrianirina on 12 


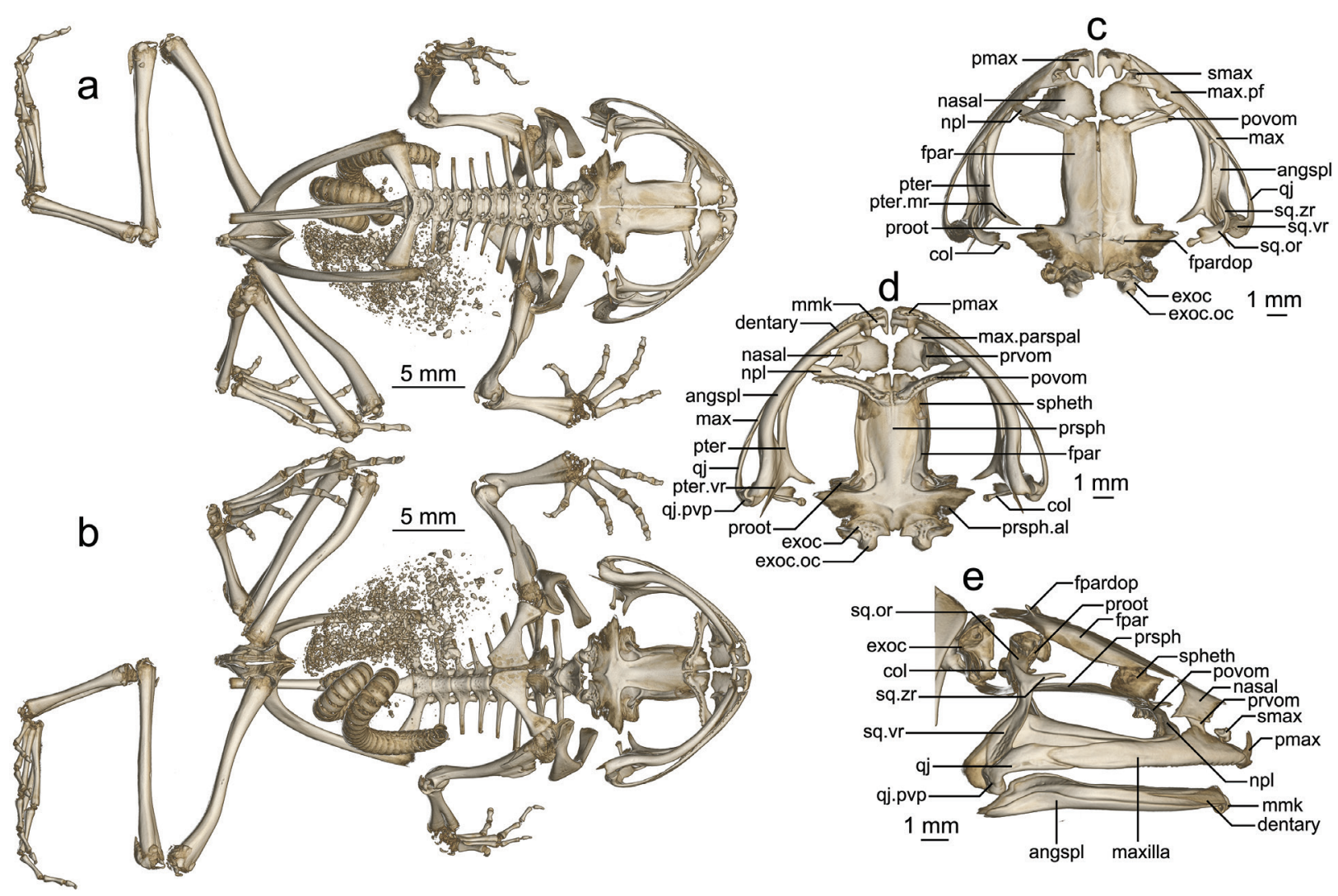

Figure 7. The skeleton of Plethodontohyla laevis (SMF 4286) rendered via micro-CT scanning. (a-b) Full skeleton in (a) dorsal and (b) ventral view. (c-e) Skull in (c) dorsal, (d) ventral and (e) lateral view. Abbreviations: angspl, angulosplenial; col, columella; exoc, exoccipital; exoc.oc, occipital condyle of exoccipital; fpar, frontoparietal; fpardop, frontoparietal dorsal process; max, maxilla; max.pf, pars facialis of maxilla; max.parspal, pars palatina of maxilla; mmk, mentomeckelian; npl, neopalatine; pmax, premaxilla; povom, postchoanal vomer; proot, prootic; prsph, parasphenoid; prsph.al, alary process of parasphenoid; prvom, prechoanal vomer; pter, pterygoid; pter.mr, medial ramus of pterygoid; pter.vr, ventral ramus of pterygoid; qj, quadratojugal; qj.pvp, posteroventral process of quadratojugal; smax, septomaxilla; sq.or, otic ramus of squamosal; sq.vr, ventral ramus of squamosal; sq.zr, zygotic ramus of squamosal; spheth, sphenethmoid. For a 3D rotational model, see Suppl. material 2.

October 2008 at Anivorano Est, village d'Ambalatenina, Forêt d'Andrarihitra (1845'56.94’S, 04857'07.20’'E, 270 m a.s.1.); ZSM 189/2016 (FGZC 5239), juvenile (ethanol-fixed and DNA sequenced), collected by F. Glaw, D. Prötzel and L. Randriamanana, on 1st January 2016 near Analalava-Foulpointe (17²2’25.39'S, 049²7'35.59'E, ca. $30 \mathrm{~m}$ a.s.1.).

Diagnosis (see also Tables 1, 5 and Figs 2-3, 6-8). A microhylid belonging to the subfamily Cophylinae, with connected lateral metatarsalia, short hindlimbs, tibiotarsal articulation not exceeding the nostril, inner metatarsal tubercle present, vomerine teeth present, clavicle absent, knob-shaped terminal phalanges, and males with a single subgular vocal sac; therefore attributed to the genus Plethodontohyla (see Appendix A of Scherz et al. 2016a). The attribution to the genus Plethodontohyla is also supported by molecular phylogenetic evidence from newly collected material (see Fig. 5). The species is characterised by the following suite of characters: (1) moderately large size (male SVL 33.0-40.3 mm; female SVL 36.8-
$42.2 \mathrm{~mm}$ ); (2) HW/HL 1.41-1.79; (3) FORL/SVL 0.500.57; (4) HIL/SVL 1.24-1.58; (5) TIBL/SVL 0.36-0.40; (6) rounded snout tip; (7) toe tips not enlarged; (8) finger tips not enlarged; (9) knob-shaped terminal phalanges of the fingers and toes; (10) smooth dorsal skin; (11) absence of a distinct dorsolateral colour border; (12) presence of a supratympanic dermal fold; (13) presence of a typically bold and generally white-bordered brown ' $\mathrm{X}$ ' marking on head; (14) tibiotarsal articulation reaching at least the tympanum and (15) TD/ED 0.33-0.52. Furthermore, the species is separated from all nominal taxa in this genus by an uncorrected pairwise distance of at least $5.5 \%$ in the sequenced 16S fragment (comparison with $P$. alluaudi in its new definition and $P$. sp. Ca01).

Plethodontohyla laevis may be distinguished from other members of the genus Plethodontohyla as follows: from $P$. inguinalis, $P$. notosticta, $P$. guentheri, P. mihani$k a$ and $P$. fonetana by non-expanded terminal digits ( $v s$. moderately to strongly expanded) and by its knob-shaped terminal phalanges of the fingers and toes (vs. T- or Y-shaped) and from all these species except $P$. fonetana 
by the absence of a dorsolateral colour border (present in all of these species but only some specimens of $P$. inguinalis). It also differs from $P$. notosticta, $P$. guentheri and $P$. mihanika by having a rounded snout tip (vs. generally pointed); from $P$. ocellata, $P$. bipunctata, $P$. brevipes, $P$. inguinalis and $P$. tuberata by smooth skin (vs. granular or tubercular); from $P$. inguinalis, $P$. notosticta, $P$. guentheri and $P$. mihanika by the presence of a supratympanic fold running from the posterior border of the eye backward until the forelimb ( $v s$. absence); from all species of Plethodontohyla except $P$. alluaudi and $P$. sp. $\mathrm{Ca} 01$ by the presence of a bold, mostly white-bordered ' $\mathrm{X}$ ' marking (see Fig. 3 for its variation) on the head ( $v s$. absence); from P. tuberata, P. bipunctata, P. brevipes and $P$. mihanika by a tibiotarsal articulation reaching at least the tympanum ( $v s$. reaching the insertion of the arms or going beyond the tip of snout in P. mihanika); and from $P$. ocellata, $P$. bipunctata, $P$. fonetana and most individuals of $P$. brevipes by lacking two symmetrical and concave thin dorsal folds ( $v s$. presence).

Plethodontohyla alluaudi (as newly circumscribed) and $P$. sp. Ca01 are morphologically the most similar species to $P$. laevis (see also Figs 3-4). For distinction from P. alluaudi, see the re-description of that species, below. Plethodontohyla laevis differs from $P$. sp. Ca01 by larger body size (SVL 33.0-42.2 vs. 27.7-31.9 mm) and smaller tympanum (TD/ED 0.33-0.52 vs. 0.55-0.63).

Plethodontohyla laevis also resembles Rhombophryne botabota, $R$. laevipes, $R$. mangabensis and $R$. savaka in external morphology and in some aspects of its colouration. It may be distinguished from all species by the presence of a bold, mostly white-bordered ' $\mathrm{X}$ ' marking on the head ( $v s$. absence), but additionally it may be distinguished from all four of these species by the absence of clavicles; from $R$. laevipes by its smaller size (SVL 36.8-42.2 mm vs. 44.5-56.3 mm), much shorter leg length (HIL/SVL 1.24-1.58 vs. 1.75-1.86) and absence of white ocelli in the inguinal region ( $v s$. presence); from $R$. laevipes and $R$. mangabensis by its smaller tympanum (TD/ED 0.33-0.52 vs. 0.57-0.73); from R. botabota, $R$. mangabensis and $R$. savaka by its larger size (SVL 36.8$42.2 \mathrm{~mm}$ vs. $20.4-32.2 \mathrm{~mm}$ ); from $R$. savaka by its slightly narrower head (HW/HL 1.41-1.79 vs. 1.80), longer relative forelimb length (FORL/SVL $0.50-0.57$ vs. 0.43), raised supratympanic fold ( $v S$. not raised) and absence of a diastema in the vomerine teeth (vs. presence); and from $R$. botabota and $R$. mangabensis by generally shorter relative tibia length (TIBL/SVL 0.36-40 vs. 0.38-0.45).

Re-description of the holotype (SMF 4286). Specimen in relatively good state of preservation (Fig. 2a, b). Right forelimb fractured (Fig. 7a, b). Ventrally slit down the midline of the whole body. SVL $38.1 \mathrm{~mm}$ (for other measurements, see Table 1). Body moderately enlarged and flattened dorsoventrally; head much wider than long and almost as wide as body; snout rounded in dorsal and lateral view; nostrils directed laterally, slightly protuberant, nearer to tip of snout than to eye; canthus rostralis distinct, concave; loreal region concave; tympanum indistinct, rounded, roughly $40 \%$ of eye diameter; supratympanic fold from eye to shoulder distinct and straight; tongue ovoid, very broad, posteriorly free and slightly notched; maxillary teeth present; vomerine teeth distinct, forming oblique transverse rows posterior to choanae, laterally approaching the maxillae and medially almost in contralateral contact; choanae ovoid. Arms robust, fingers bearing marked single subarticular tubercles and hands bearing indistinct paired outer metacarpal tubercles; large, slightly protruding inner metacarpal tubercle; fingers without webbing; relative length of fingers $1<2=4<3$, fourth finger roughly equal in length to second; finger disks not enlarged; nuptial pads absent. Hindlimbs robust; tibiotarsal articulation reaching the tympanum when hindlimb adpressed along body; tibia length $38.8 \%$ of SVL; lateral metatarsalia connected; distinct inner and less distinct outer metatarsal tubercles present; only traces of webbing between toes; relative length of toes $1<2<5<3<4$; third toe distinctly longer than fifth. Skin on dorsum and venter smooth; supratympanic fold whitish. Colour of iris indistinguishable.

Colouration. After more than a century in preservative (holotype collected in September 1904) colouration is faded. Dorsum light brown with darker brown-black spots, markings and presence of a bold X-shaped marking bordered with a white line on the head behind the eye. Colouration of the proximal dorsal portion of the hindlimbs mottled with dark brown markings on a cream background colour; the same colouration extends into the inguinal region. Colouration of the distal dorsal portion of the hindlimbs light brown with faint brown crossbands. Sides of head and tympanic region brownish, with darkener flecks. Ventral skin markedly pigmented: throat and chest mottled brown and cream, abdomen and ventral legs cream, becoming increasingly mottled with faint brown distally. The colouration in life of this specimen is not known.

Osteology. In the following, we describe notable and important diagnostic characters of Plethodontohyla laevis based on SMF 4286 (Figs 2, 6-7) and the newly collected specimen MRSN A6340 (Fig. 8). PDF-embedded 3D models of these skeletons are provided as Suppl. materials 2 and 5.

Right humerus fractured in SMF 4286. Skeleton of SMF 4286 relatively poorly ossified, such that the carpals, knee and heel joints and pubis are not visible in the micro-CT scans. The skeleton of MRSN A6340 is comparatively well ossified. Vomerine teeth anteriorly convex, long, occupying the whole postchoanal vomer, separated medially by a small gap. Palatine processes of premaxilla subequal in width and length. Prechoanal vomer flat and triradiate, the lateral ramus closer to the anterior end. Premaxilla and maxilla bearing teeth. Nasals large, broad, not in contact with other bones. Sphenethmoid only laterally ossified. Extensive calcification present inside the braincase of MRSN A6340. Posterior ramus of pterygoid 

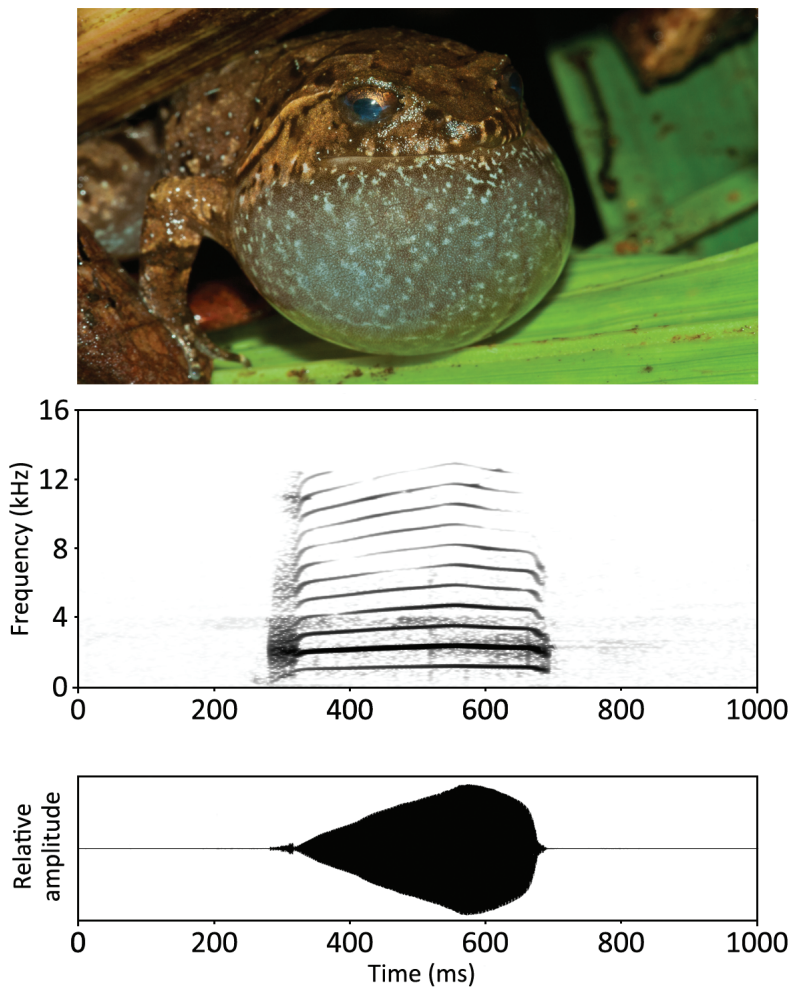

Figure 8. Audiospectrogram and corresponding oscillogram of the advertisement call of Plethodontohyla laevis recorded at Betampona Strict Nature Reserve on 18 November 2007 $\left(22: 30 \mathrm{~h}, 21^{\circ} \mathrm{C}\right)$. Calling male MRSN A6340 (top).

extremely long and broad. Transverse ridge across posterior of frontoparietals. Weakly descending lateral flange of frontoparietal. Clavicle absent. Coracoids with weak notches for the attachment of the procoracoid cartilage. Cleithrum broad. Terminal phalanges of fingers knobbed. Finger phalangeal formula 2-2-3-3. Neural spines present on presacrals 2 and 3. Sacrum thin. Iliosacral articulation type IIA/B sensu Emerson (1979). Urostyle bearing a strong, straight dorsal ridge for almost its entire length; articulation bicondylar. Iliac shafts bearing weak dorsal crests; possessing a shallow oblique groove and lacking a dorsal tubercle. Leg bones lacking crests. Toe phalangeal formula 2-2-3-4-3.

Colouration in life based on recently collected material. The colouration in life is remarkably variable. Dorsal colouration is a range of brown tones, while ventral colouration contains elements of grey, black and beige. The most consistent element is a more or less bold, X-shaped marking on the back of the head, with the anterior arms of the $\mathrm{X}$ reaching onto the posterior of each eye, and the posterior arms reaching posteriorly to either join the dorsal pattern (typically fading) or remaining clearly distinct in the suprascapular region. This distinctive marking is present in the dorsal colouration also in juveniles (B. Ferrier, personal communication) and is clear in most adults, though it can sometimes be faded and not clearly distinct from the rest of the dorsal colouration. Posterior to this ' $\mathrm{X}$ ', the dorsum is typically dark brown mottled with black, with generally clearly defined, subsymmetrical light brown markings distributed over the dorsum. In some specimens there are also black spots on the flanks. The lateral head is typically light brown (the colour of the dorsal markings), the supratympanic fold somewhat lighter and the tympanum containing a dark spot. In the inguinal region, black spots and light brown spots merge to form lines, but do not form a clearly defined, single black spot as in e.g. P. alluaudi. The dorsal thigh is mottled black with light brown, semi-regular spots, or with moderately defined dark and light crossbands, whereas the dorsal shank is a murky brown with irregular light brown spots or light brown with dark crossbands. The dorsal forelimb is as the shank. The ventral body is beige in base colour, with irregular dark brown mottling over the chin, which can be totally black in males, becoming less regular posteriorly over the abdomen and being free of maculations over the hip. The ventral shank is mostly beige, sometimes with dark spots. A light brown annulus is present before the tip of each finger.

Variation. Morphometric variation is given in Table 1. No remarkable variation in general morphology exists between the holotype and the newly collected material, except that the second finger is shorter than the fourth in newly collected specimens. Colouration variation has been discussed in the above section, and is merely more vivid and distinct in the new material than the holotype. Females lack the single subgular vocal sac that can be highly extensible (Fig. 8). MRSN A6189 and MRSN A6181 are slightly less pigmented than MRSN A6340 and the colouration of the proximal dorsal portion of the hindlimbs (mottled with black markings on a cream background colour) extends forward to lateral midbody and backwards to the tibiotarsal articulation on the ventral side of the hindlimb.

Natural history. Little information is available on this species. The eight new specimens were found active on the ground during the day or during the night, and this species was also found moderately active in dry conditions (after several days of no rainfall). In November 2013 one individual (not collected) was encountered along a drift fence during a rainy night. ZSM 980/2013 was encountered hidden in the leaf litter at the base of a Ravenala madagascariensis and ZSM 189/2016 was active in the leaf litter during the day. No information on the reproductive biology of this species is currently known. In 2007, a group of males were heard calling during rainfall. Individuals were calling from within the leaf litter or at the opening of a burrow, into which they can easily disappear upon detection. The holotype has a nearly intact millipede in its stomach (see Fig. 7). This is the only diet record currently available for this species.

Distribution and conservation status. Plethodontohyla laevis is known from (1) the type locality Sakana (whence no recent records for the species are known), (2) Betam- 
pona Natural Reserve, (3) Marovato, (4) Anivorano Est, (5) Analalava-Foulpointe and (6) the Réserve Privée (RP) d'Ambodiriana (only photographic records are available from this locality) (Figs 1-3). All these sites are distributed at low altitudes in the central- to North-East of Madagascar. Altitudinal distributional range reaches from sea level to ca. $700 \mathrm{~m}$ a.s.1.. Due to the severe habitat degradation of the lowland rainforest in the northeast of Madagascar it is likely that the species is locally extinct at its type locality. Surveys in Zahamena Natural Reserve so far failed to report this species, but a more thorough investigation of the area is required to confirm the presence or absence of this species in that area. As noted above, the record of the species from the central highland (Ankazobe) is dubious and must be confirmed by further fieldwork in this area and/or examination of the material cited by Blommers-Schlösser (1975).

The species occurs at least in two protected areas, where it seems to be a relatively abundant although it is a species with secretive habits. Nevertheless, its distribution is highly fragmented, its extent of occurrence is quite limited (minimum convex polygon $=9770.92 \mathrm{~km}^{2}$ ) and it is threatened by on-going habitat destruction. These factors (range under $20,000 \mathrm{~km}^{2}$, severely fragmented distribution and on-going habitat destruction) qualify $P$. laevis as Vulnerable under criterion B1ab(iii) of the IUCN Red List (IUCN 2012).

Acoustic repertoire. Advertisement calls were recorded from a single male (MRSN A6340) at Betampona (Maintimbato: $17^{\circ} 53$ '35.50'S, 049¹3'41.30”E, $283 \mathrm{~m}$ a.s.1.) on 18 November 2007 , at 22:30 h at an air temperature of $21{ }^{\circ} \mathrm{C}$ (Rosa et al. 2011, track \#50) (Fig. 8, Table 3). Each call consisted of a single loud note repeated after long, regular intervals, starting as unharmonious sound, but being tonal for most of its duration. They were slightly frequency-modulated in their tonal part and lasted 391-422 ms $(407 \pm 12.7, n=4)$. We recorded one inter-call interval of $47 \mathrm{~s}$. The fundamental frequency of the tonal part was 0.89-1.40 kHz with a dominant frequency band (frequency containing the greatest sound energy) between 1.82$2.53 \mathrm{kHz}$. Up to 10 harmonics were visible on the spectrogram and no attenuation of any of the harmonics was observed. The call of Plethodontohyla laevis is overall quite similar to the other species of this genus, and also members of the genus Rhombophryne (e.g. Lambert et al. 2017), but seems to have a lower repetition rate. Although we recorded only one of these long inter-call intervals, the recording was made on a rainy night, with more males calling simultaneously, all with long inter-call intervals.

\section{Plethodontohyla alluaudi (Mocquard, 1901)}

Figs 2c, d, 4a, 6, 9, Suppl. materials 1, 3, 6

Remarks. Sequences of this species have been referred to as Plethodontohyla bipunctata Andohahela by Wollenberg et al. (2008), Vieites et al. (2009), Perl et al.
(2014) and Scherz et al. (2016a). Blommers-Schlösser (1975) referred to a specimen from Ampasinambo (20³1'25.0'S, $048^{\circ} 01^{\prime} 13.7^{\prime}$ 'E) as P. brevipes, but later corrected this to P. alluaudi (Blommers-Schlösser and Blanc 1991). This locality is between the distributions of $P$. alluaudi (as refined here) and P. laevis, and we therefore consider this record uncertain until the specimen (ZMA 6689) has been re-examined.

Identity and redefinition. The original description of Dyscophus alluaudi is based on a single specimen of 47.4 $\mathrm{mm}$ SVL from the generic locality 'Fort Dauphin'. After the examination and comparison of the type material with recently collected material in south-eastern Madagascar close to the type locality of Dyscophus alluaudi, we here reassign this species to the genus Plethodontohyla. We therefore re-describe and redefine Plethodontohyla alluaudi based on the holotype (including its osteology via micro-CT scanning), on the holotype of $P$. laevis tsianovohensis and the recently collected material from Andohahela, Tsitongambarika and Sainte Luce.

Holotype. MNHN 1901.235, an adult female collected by M. Alluaud in 'Fort Dauphin'.

Referred material. MNHN 1936.0047, holotype of $P$. laevis tsianovohensis, an adult female collected by R. Heim between 1934 and 1935 in Tsianovoha, East Madagascar. ZSM 89/2004 (FGZC 161), an unsexed adult individual (DNA sequenced and included in Wollenberg et al. 2008: Accession number EU341068), collected by F. Glaw, M. Puente, M. Thomas and R. Randrianiaina on 31 January 2004 at Andohahela, (between Isaka-Ivondro and Eminiminy; 2445'00"S, 04651'00'E, ca. 230 m a.s.1.), Toliara Province, south-eastern Madagascar; UADBA-A 27994 (FGZC 160), an unsexed adult individual, collected by F. Glaw, M. Puente, M. Thomas and R. Randrianiaina on 31 January 2004 at Andohahela (between Isaka-Ivondro and Eminiminy; 244'00”S, 04651'00”'E, ca. $230 \mathrm{~m}$ a.s.1.), Toliara Province, south-eastern Madagascar; MRSN uncatalogued (FAZC 15423), unsexed adult individual (ethanol-fixed and DNA sequenced), collected by F. Andreone and G.M. Rosa on 29 February 2012 at Tsitongambarika Forest Reserve (Anosyenne Chain; 24³3’32.10”S, 04711'24.90'E, $32 \mathrm{~m}$ a.s.1.); UADBA-A 62219, an unsexed adult individual, collected by S. Megson on 22 July 2013 at Sainte Luce $\left(24^{\circ} 47^{\prime} 12^{\prime \prime}\right.$ S, 047 09'45'E, ca. 19 m a.s.1.), Toliara Province, south-eastern Madagascar; UADBA-A 62224, an unsexed juvenile individual, collected by S. Megson on 17 July 2013 at Sainte Luce (2446'87'S, $047^{\circ} 10^{\prime} 24^{\prime \prime}$ E, ca. 7 m a.s.1.), Toliara Province, south-eastern Madagascar.

Diagnosis (see also Tables 1, 5 and Figs 2, 4, 6, 9). A large microhylid belonging to the subfamily Cophylinae, with connected lateral metatarsalia, short forelimbs (FORL/SVL 0.47-0.58), short hindlimbs, 


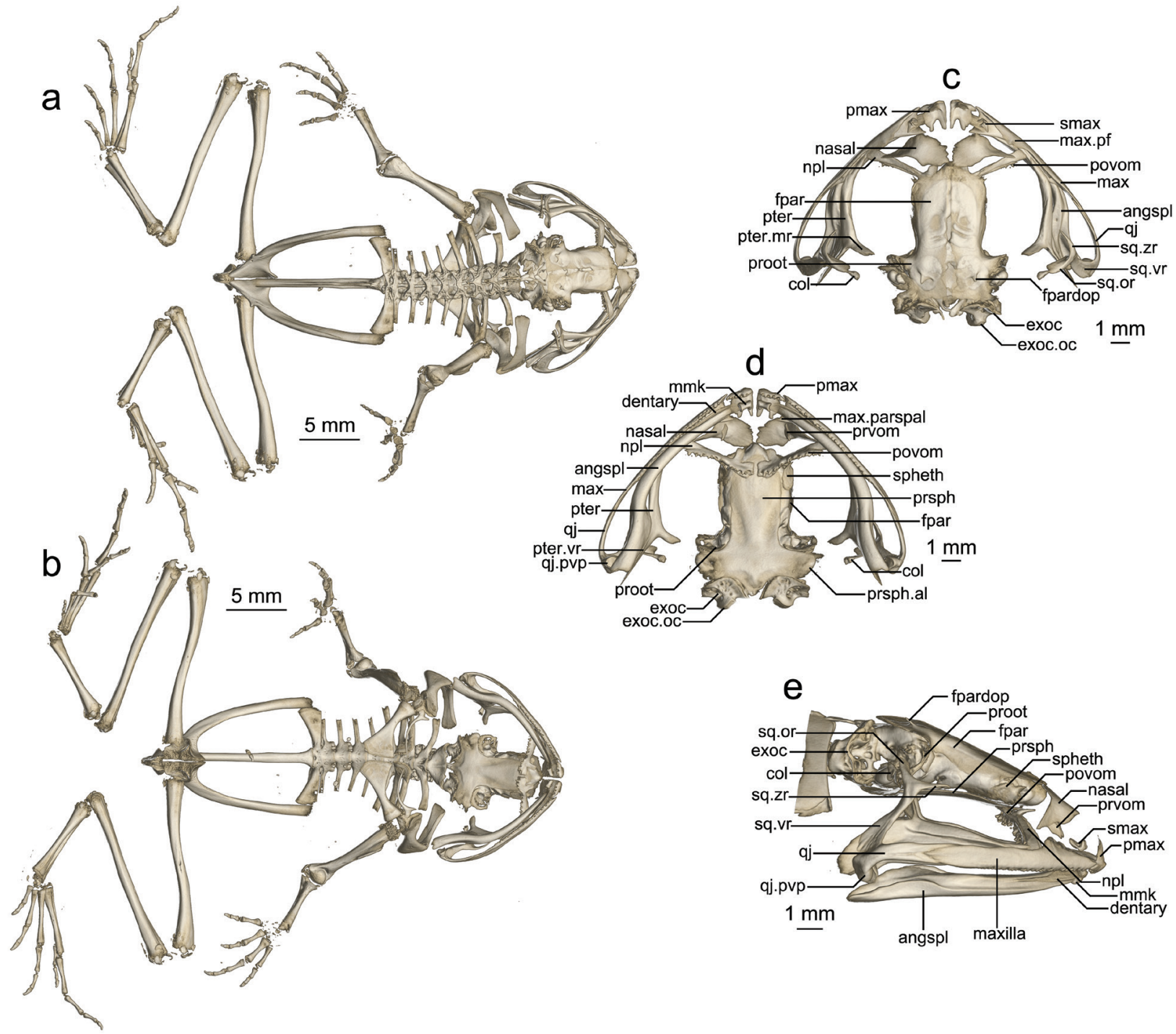

Figure 9. The skeleton of Plethodontohyla alluaudi (MNHN 1901.235) rendered via micro-CT scanning. (a-b) Full skeleton in (a) dorsal and (b) ventral view. (c-e) Skull in (c) dorsal, (d) ventral and (e) lateral view. Abbreviations are as in Fig. 7. For a 3D rotational model, see Suppl. material 1.

tibiotarsal articulation reaching the insertion of the arms, inner metatarsal tubercle present, maxillary and vomerine teeth present, clavicle absent or highly reduced, knob-shaped terminal phalanges and males with a single subgular vocal sac; therefore attributed to the genus Plethodontohyla (see Appendix A of Scherz et al. 2016a). The attribution to the genus Plethodontohyla is also supported by phylogenetic molecular evidence from newly collected material (see Fig. 5). The species is characterised by the following suite of characters: (1) moderately large size (SVL 28.8-58.0 mm); (2) HW/ HL 1.67-1.85; (3) FORL/SVL 0.47-0.58; (4) HIL/ SVL 1.25-1.47; (5) TIBL/SVL 0.34-0.39; (6) rounded snout tip; (7) toe tips not enlarged; (8) finger tips not enlarged; (9) knob-shaped terminal phalanges of the fingers and toes; (10) smooth dorsal skin; (11) absence of a distinct dorsolateral colour border; (12) presence of a supratympanic fold; (13) presence of a bold white-bordered ' $\mathrm{X}$ ' marking on head; (14) tibiotarsal articulation reaching the insertion of the arm; (15) TD/ ED 0.33-0.66. Furthermore, the species is separated from all nominal taxa in this genus by an uncorrected pairwise distance of at least 5.6\% (comparison with $P$. tuberata; genetic distance of $5.8 \%$ with $P$. laevis). The genetic distance with $P$. sp. $\mathrm{Ca} 01$ is $2.9 \%$.

Plethodontohyla alluaudi may be distinguished from other members of the genus Plethodontohyla as follows: from P. inguinalis, $P$. notosticta, P. guentheri, $P$. mihanika and $P$. fonetana by non-expanded terminal digits (vs. moderately to strongly expanded) and by its knob-shaped terminal phalanges of the fingers and toes (vs. T- or Y-shaped) and from all these species except $P$. fonetana by the absence of a dorsolateral colour border (present in all of these species but only some specimens of $P$. inguinalis). It also differs from $P$. notosticta, $P$. guentheri and $P$. mihanika by having a rounded snout 
tip (vs. generally pointed); from P. ocellata, P. bipunctata, $P$. brevipes, $P$. inguinalis and $P$. tuberata by smooth skin (vs. granular or tubercular); from $P$. inguinalis, $P$. notosticta, $P$. guentheri and $P$. mihanika by the presence of a supratympanic fold running from the posterior border of the eye backward until the forelimb ( $v s$. absence); from all species of Plethodontohyla except $P$. laevis and $P$. sp. Ca01 by the presence of a bold white-bordered ' $\mathrm{X}$ ' marking on the head (vs. absence); from $P$. laevis, $P$. sp. Ca01, P. ocellata, P. inguinalis, P. notosticta, P. guentheri, $P$. fonetana and $P$. mihanika by a tibiotarsal articulation reaching the insertion of the arms (vs. see Table $5)$; and from $P$. brevipes $(\mathrm{n}=6)$ by a generally wider head (HW/HL 1.67-1.85 vs. 1.53-1.71, Mann-Whitney U-test, $P=0.032$ ), a generally smaller tympanum (TD/ ED 0.33-0.66 vs. 0.60-0.79, Mann-Whitney U-test, $P=$ $0.025)$, tendency toward larger relative hand size (HAL/ SVL 0.23-0.28 vs. 0.21-0.24, Mann-Whitney U-test, $P$ $=0.051$ ), larger inner metatarsal tubercle (IMTL/FOL 0.13-0.17 vs. 0.09-0.13) and presence of a bold ' $\mathrm{X}$ ' marking on the head ( $v s$. absence).

Plethodontohyla laevis and P. sp. Ca01 are morphologically the most similar species to P. alluaudi. Plethodontohyla alluaudi can be distinguished from P. laevis by frequent presence of inguinal spots ( $v s$. general absence), generally larger tympanum size (TD/ED $0.33-0.66$ [0.53-0.66 for three of the four examined specimens] vs. 0.33-0.52) and tendency toward larger relative hand size (HAL/SVL 0.23-0.28 vs. 0.21-0.25, Mann-Whitney U-test, $P=0.085)$.

Re-description (based on MNHN 1901.235). Specimen in relatively good state of preservation (Figs 2, 6, 9). A cross-shaped incision made over the pectoral girdle, a lateral incision on the left side and a number of incisions on the lower back. A strong transverse fold is present at the posterior head, certainly a fixation artefact. SVL 47.4 $\mathrm{mm}$ (for other measurements, see Table 1). Body large and robust; head much wider than long (HW/HL 1.85) and almost as wide as body; snout rounded in dorsal and lateral view; nostrils directed laterally, slightly protuberant, nearer to tip of snout than to eye; canthus rostralis distinct, concave; loreal region concave, oblique; tympanum slightly distinct, rounded, TD/ED 0.53 ; supratympanic fold from eye to shoulder distinct and curved; tongue ovoid, very broad, posteriorly free and not notched; mandible damaged at the midline so that the two halves are distinguishable externally; maxillary teeth present; vomerine teeth distinct, forming oblique curved rows posterior to choanae, laterally approaching the maxillae and medially almost in contralateral contact; choanae ovoid. Arms robust, fingers bearing marked single subarticular tubercles and hands bearing indistinct outer metacarpal tubercles; large, protruding inner metacarpal tubercle; fingers without webbing; relative length of fingers $1<2<4<3$, fourth finger slightly longer than second; finger disks not enlarged; nuptial pads absent. Hindlimbs robust; tibiotarsal articulation reaching the insertion of the arm when hindlimb adpressed along body; TIBL/ SVL 0.34; lateral metatarsalia connected; distinct inner and less distinct outer metatarsal tubercles present; only traces of webbing between toes; relative length of toes $1<2<5<3<4$; third toe distinctly longer than fifth. Skin on dorsum smooth; supratympanic fold whitish. Colour of iris indistinguishable.

Colouration. After over a century in preservative, the colouration is strongly faded, and several details of the pattern originally illustrated by Mocquard (1901) are only barely distinguishable. The base colouration of the whole specimen is cream-brown. Large dark brown markings in the inguinal region remain, as do oblique dark brown bars on the anterior thigh and faint brown spots on the posterior thigh. A faint trace of the large X-shaped marking on the posterior head is present only as the outlines of this shape. The ventral skin is translucent cream, and muscles are visible through it. No other traces of colouration remain. The colouration in life of this specimen is not known.

Osteology. In the following, we describe notable and important diagnostic characters of Plethodontohyla alluaudi based on MNHN 1901.235, MNHN 1936.47 and ZSM 89/2004 (Fig. 6). PDF-embedded 3D models of these skeletons are provided as Suppl. materials 1, 3 and 6.

Ossification is variable, but lowest in ZSM 89/2004 where the knees and carpals are not visible. Vomerine teeth anteriorly convex, with a distinct angle in MNHN 1936.47 not present in the other two specimens, covering the whole postchoanal vomer, separated medially by a small gap. Palatine processes of premaxilla subequal in length, the medial process thinner than the lateral process. Prechoanal vomer flat and triradiate, the lateral ramus around its midpoint, but weak or missing in MNHN 1936.47. Nasals large and broad, not in contact with other bones. Sphenethmoid laterally closed, brain case of ZSM 89/2004 and MNHN1901.235 with some internal mineralisation. Posterior ramus of pterygoid extremely long and broad. Strong transverse ridge across posterior of frontoparietals most raised at its lateral extremities, strongly descending lateral flange of frontoparietal. The right coracoid of MNHN 1901.235 is fractured mid-way along its length. Clavicles are present only in MNHN 1901.235, where they are reduced to thin slivers. The coracoid possesses a strong notch for the attachment of the procoracoid cartilage. Cleithrum broad. Terminal phalanges of fingers knobbed. Finger phalangeal formula 2-2-3-3. Neural spines present on presacrals 2 and 3. Sacrum relatively thin, broadening laterally. Iliosacral articulation type IIA/B sensu Emerson (1979). Urostyle bearing a strong, straight dorsal ridge for almost its entire length; articulation bicondylar. Iliac shafts bearing weak dorsal crests; possessing a shallow oblique groove and lacking a dorsal tubercle. Leg bones lacking crests. Toe phalangeal formula 2-2-3-4-3. 
Table 5. Morphological variation in the analysed specimens of Plethodontohyla spp. Abbreviations not identified in the text: TT, Toe Tips (1, not enlarged, 2, enlarged); FT, Finger Tips (1, not enlarged, 2, enlarged); TP, Terminal Phalanges (K, knob-shaped, T, T-shaped, Y, Y-shaped); DDL, Dorsolateral Line, a narrow white dorsolateral line delimiting a sharp difference between the dorsal colouration and the uniformly dark flanks, extending from the tip of the snout backward until the inguinal region (+, presence, - absence, $(+)$, not always present); Sk, Skin (1, smooth, 2, granular, 3, with tubercles); RID, Ridge, supratympanic dermal fold $(+$, presence, - absence); $X$, bold ' $X$ ' marking on the head between the eye bordered by a thin while line (+, presence, - absence); DDF, Dorsal Dermal Folds, two symmetrical and concave thin dorsal folds (+, presence, - absence); TTA, Tibiotarsal Articulation ( 1 , reaching the tympanum, 2 , reaching the insertion of the arms, 3 , reaching the eye, 4 , extending beyond the eye, $*$ at least); ST, Snout tip (1, rounded, 2, pointed).

\begin{tabular}{|c|c|c|c|c|c|c|c|c|c|c|c|c|c|c|c|}
\hline ID code & Genus & Species & Locality & Sex & Status & TT & FT & TP & DLL & SK & RID & $x$ & DDF & TTA & ST \\
\hline SMF 4286 & Phrynocara & laeve & Sakana & $\mathbf{F}$ & HT & 1 & 1 & $\mathrm{~K}$ & - & 1 & + & + & - & $\mathrm{n} / \mathrm{a}$ & 1 \\
\hline MRSN A6189 & Plethodontohyla & laevis & Betampona & $\mathrm{F}$ & - & 1 & 1 & $\mathrm{~K}$ & - & 1 & + & + & - & $1^{*}$ & 1 \\
\hline MRSN A6181 & Plethodontohyla & laevis & Betampona & $\mathrm{F}$ & - & 1 & 1 & $\mathrm{~K}$ & - & 1 & + & + & - & $1 *$ & 1 \\
\hline MRSN A6340 & Plethodontohyla & laevis & Betampona & $\mathrm{M}$ & - & 1 & 1 & $\mathrm{~K}$ & - & 1 & + & + & - & $1^{*}$ & 1 \\
\hline ZSM 980/2013 & Plethodontohyla & laevis & Betampona & $M$ & - & 1 & 1 & $\mathrm{~K}$ & - & 1 & + & + & - & $1^{*}$ & 1 \\
\hline MRSN A6674 & Plethodontohyla & laevis & Marovato & $\mathrm{F}$ & - & 1 & 1 & $\mathrm{~K}$ & - & 1 & + & + & - & 3 & 1 \\
\hline MRSN A6787 & Plethodontohyla & laevis & Anivorano Est & $M$ & - & 1 & 1 & $\mathrm{~K}$ & - & 1 & + & + & - & $1 *$ & 1 \\
\hline MNHN 1901.235 & Dyscophus & alluaudi & Fort Dauphin & $\mathbf{F}$ & HT & 1 & 1 & $\mathrm{~K}$ & - & 1 & + & + & - & 2 & 1 \\
\hline MNHN 1936.47 & Plethodontohyla & $\begin{array}{l}\text { laevis } \\
\text { tsianovohensis }\end{array}$ & Tsianovoha & $\mathbf{F}$ & HT & 1 & 1 & K & - & 1 & + & + & - & $n / a$ & 1 \\
\hline ZSM 89/2004 & Plethodontohyla & alluaudi & Andohahela & - & - & 1 & 1 & $\mathrm{~K}$ & - & 1 & + & + & - & $2^{*}$ & 1 \\
\hline FAZC 15423 & Plethodontohyla & alluaudi & $\begin{array}{c}\text { Tsitongambarika } \\
\text { (Anosyenne Chain) }\end{array}$ & - & - & 1 & 1 & K & - & 1 & + & + & - & $n / a$ & 1 \\
\hline $\begin{array}{l}\text { UADBA-A } 27994 \\
(\text { FGZC 160) }\end{array}$ & Plethodontohyla & alluaudi & Andohahela & - & - & 1 & 1 & K & - & 1 & + & + & - & $\mathrm{n} / \mathrm{a}$ & 1 \\
\hline ZCMV 555 & Plethodontohyla & sp. $\mathrm{CaO} 1$ & Ambatolahy & - & - & 1 & 1 & $\mathrm{n} / \mathrm{a}$ & - & $\mathrm{n} / \mathrm{a}$ & + & + & - & $\mathrm{n} / \mathrm{a}$ & 1 \\
\hline ZSM 855/2006 & Plethodontohyla & sp. $\mathrm{CaO} 1$ & Imaloka & - & - & 1 & 1 & $\mathrm{~K}$ & - & 1 & + & + & - & 1 & 1 \\
\hline ZSM 856/2006 & Plethodontohyla & sp. CaO1 & Imaloka & - & - & 1 & 1 & $\mathrm{~K}$ & - & 1 & + & + & - & 1 & 1 \\
\hline MRSN A3221 & Plethodontohyla & tuberata & Manjakatompo & - & - & 1 & 1 & $\mathrm{~K}$ & - & 3 & + & - & - & 2 & 1 \\
\hline MRSN A2859 & Plethodontohyla & ocellata & Ranomafana & - & - & 1 & 1 & $\mathrm{~K}$ & - & 2 & + & - & - & $1 *$ & 1 \\
\hline ACZCV 0101 & Plethodontohyla & ocellata & Betampona & - & - & 1 & 1 & $\mathrm{~K}$ & - & 2 & + & - & + & $1^{*}$ & 1 \\
\hline ZSM 5204/2005 & Plethodontohyla & bipunctata & Andohahela & - & - & 1 & 1 & $\mathrm{~K}$ & - & 2 & + & - & + & $2^{*}$ & 1 \\
\hline ZSM 854/2006 & Plethodontohyla & brevipes & Imaloka & - & - & 1 & 1 & K & - & 2 & + & + & + & 2 & 1 \\
\hline MRSN A2476 & Plethodontohyla & inguinalis & Kalambatritra & - & - & 2 & 2 & $T$ & $(+)$ & 2 & - & - & - & 3* & 1 \\
\hline MRSN A5653 & Plethodontohyla & notosticta & Sahavontsira & - & - & 2 & 2 & $\mathrm{~T}$ & + & 1 & - & - & - & 3 & 2 \\
\hline ZSM 61/2005 & Plethodontohyla & guentheri & Marojejy & $\mathrm{F}$ & $\mathrm{HT}$ & 2 & 2 & $\mathrm{~T}$ & + & 1 & - & - & - & 3 & 2 \\
\hline ZSM 123/2006 & Plethodontohyla & fonetana & Tsingy de Bemaraha & $\mathrm{F}$ & $\mathrm{HT}$ & 2 & 2 & Y & - & 1 & + & - & + & 1 & 1 \\
\hline ZSM 1087/2001 & Plethodontohyla & mihanika & Andasibe & $\mathrm{M}$ & PT & 2 & 2 & $\mathrm{~T}$ & + & 1 & - & - & - & $4^{*}$ & 2 \\
\hline
\end{tabular}

Colouration in life based on recently collected material. Dorsally a greenish brown colouration, with a distinct dark brown ' $\mathrm{X}$ ' marking on the posterior head, with the anterior arms of the X over the eyes, and the posterior arms reaching the suprascapular region, bordered with a fine, light brown line. The dorsal colouration is flecked with white, with especially large white spots over the ends of the iliac shafts. A large blackish inguinal spot bordered with a white line is present. The flank colouration is marbled brown with white spots. The supratympanic fold is whitish, and forms a weak colour border between the dorsal colouration and the richer brown lateral head. The arm is anteriorly darker brown, almost blackish. The dorsal thigh is also darker brown, but not blackish. The ventral colouration is translucent and thus peach over the chin and pinkish over the abdomen, invaded on the sides behind the pectoral girdle by brown flecks, but not meeting medially. The ventral thighs are also pinkish, anteriorly and posteriorly with brown flecks. A yellow-cream annulus is present before the tip of each finger.
Variation. Morphometric variation is given in Table 1. The holotype and MNHN 1936.47 are considerably larger than the newly collected material. MNHN 1936.47 apparently lacks inguinal spots, but its colouration is faded to the point where these might have disappeared. UADBA-A 27994 has a considerably smaller tympanum diameter than the other specimens (TD/ED 0.34 vs. 0.53-0.66). The holotype has the shortest forelimbs (FORL/SVL 0.47 vs. 0.53-0.58) and hindlimbs (HIL/SVL 1.25 vs. 1.41-1.47).

Natural history. At Andohahela specimens were found in the leaf litter of rainforest during the day. In Anosyenne Chain (Tsitongambarika) the specimen was found at night under leaf litter not far from the edge of the forest patch. Males from the Sainte Luce population have been heard calling in large choruses from hidden positions after heavy rainfall during the day and night, both inside the forest and in more open areas. During such periods choruses consist of many dozens of individuals. Individuals are extremely hard to detect and cease calling if they notice any distur- 
bance, retreating into their burrows and hiding places in the forest floor. Individuals may be seen travelling above ground on rainy nights, particularly in areas in close proximity to small water bodies such as shallow forest streams, the margins of swamps and even in ephemeral mud puddles. At Sainte Luce, one adult specimen was found during the day, in light rainfall, underneath a log in littoral forest; and a juvenile specimen was found during the day in dry weather in severely degraded habitat, inside the shell of a deceased large land snail. The body of this individual became bloated during initial handling. In mature forest, adult individuals have also been observed beneath dead Pandanus leaves, under dead fallen trees and dead logs. No feeding or reproductive behaviour has been observed.

Distribution and conservation status. Plethodontohyla alluaudi is known from (1) the type locality 'Fort Dauphin' (or Tolagnaro, whence there are no recent records for the species, although this collection site was probably a very generic one), (2) Andohahela National Park, (3) Tsitongambarika Forest Reserve, (4) Sainte Luce and (5) Tsianovoha. Observations in Sainte Luce have been made in two of the largest forest fragments (fragments S7 and S9). All these sites are distributed at low altitudes in the East or south-eastern of Madagascar. Altitudinal distributional range extends from sea level to ca. $230 \mathrm{~m}$ a.s.l.. It is not clear where the type locality of this species is, but if it was a forest in the vicinity of Tolagnaro, then it is quite possible that it has been extirpated due to forest destruction there. Surveys in nearby Nahampoana and Mandena forests have so far failed to report this species, but a more thorough investigation of the area is required to confirm the presence or absence of this species in that area.

The species occurs at least in three protected areas, where it seems to be a relatively abundant although it has very secretive habits. Nevertheless, its distribution is highly fragmented, its extent of occurrence is quite limited (minimum convex polygon $=5372.81 \mathrm{~km}^{2}$ ) and it is threatened by on-going habitat destruction. As for $P$. laevis, it therefore qualifies as Vulnerable under IUCN Red List criterion B1ab(iii) (IUCN 2012).

Acoustic repertoire. Advertisement calls were recorded from a chorus of males at Sainte Luce $\left(24^{\circ} 46^{\prime} 51.72^{\prime}\right.$ 'S, $047^{\circ} 10^{\prime} 13.14^{\prime \prime} \mathrm{E} ; 10 \mathrm{~m}$ a.s.1.) on 30 June 2015, around 15:00 $\mathrm{h}$ at an air temperature of $24^{\circ} \mathrm{C}$ (Table 3 ). This is a preliminary acoustic description due to the low quality of the available recordings (background noise and overlapping of several calls), which has compromised the obtainment of some parameters (Table 3). The following parameters could be assessed: the call consisted of a single note (soft whistle) repeated after apparently regular intervals. Calls lasted 320-560 ms $(478 \pm 109, \mathrm{n}=4)$. The dominant frequency seems to range from 1.4 to $2.1 \mathrm{kHz}$, however these values should be interpreted with caution since the distance from the calling individuals might complicate the distinction of harmonics. A more accurate bioacoustic analysis will be needed when new data are available.

\section{Taxonomic challenges in cophyline taxonomy}

The resurrection of Plethodontohyla laevis and transfer of Dyscophus alluaudi from Rhombophryne to the genus Plethodontohyla brings this genus to 11 nominal species (not including the dubious $P$. angulifera Werner, 1903), and Rhombophryne down to 18. At present, only two other candidate species are known from Plethodontohyla (one from Tsaratanana and $P$. sp. Ca01 from Ambatolahy and Imaloka, which might be conspecific with P. alluaudi), but preliminary results suggest that the undescribed diversity in this genus is still widely unexplored and it will probably wind up being as great as it was for Rhombophryne (Vieites et al. 2009, Perl et al. 2014), with at least four additional undescribed species still awaiting formal description (A. Crottini et al. unpublished data). With this much-needed clarification of these historical names, we are now finally able to make larger progress on the taxonomy of this genus.

The cophyline microhylids are a case study of the need for an integrative taxonomic approach (Dayrat 2005). Taxonomic action like the synonymisation of Plethodontohyla laevis with $P$. alluaudi was made on the basis of external morphological differences and the state of the pectoral girdle, but could not take into account other aspects of skeletal morphology, nor could it account for genetics, as it was done before micro-CT and genetic methods were widely available, and based on single individuals (Blommers-Schlösser and Blanc 1991). Our approach, combining external morphology and osteology without damaging the type specimens of old and recently collected material, and the availability of genetic samples from several populations in Madagascar largely resembling the holotypes of $P$. laevis and $P$. alluaudi, provides a more robust hypothesis on the identities of these species than has been possible in the past.

Cophyline microhylids are still the least understood amphibians of Madagascar and the recent major advances in cophyline taxonomy would not have been possible without the collection of new material. However, more extensive and widespread collection of specimens from across Madagascar is still needed to fully characterize species distribution ranges and clarify their systematics. At least two new genera are still in need of description (Scherz et al. 2016a), basal relationships among the different genera are still poorly resolved, and even at the intra-generic level there are still several unresolved relationships (Scherz et al. 2016a). The intra-genus relationships in Plethodontohyla are no exception to this. Although the monophyly of the genus is now relatively well established (Andreone et al. 2005, Wollenberg et al. 2008, Scherz et al. 2016a), one study (Pyron and Wiens 2011) has found them to be polyphyletic, with one poorly supported group (containing $P$. inguinalis, $P$. tuberata, $P$. bipunctata, $P$. brevipes and $P$. ocellata) found to be the sister clade of all cophylines but Anodonthyla, and the other group (although with no support) composed of $P$. mihanika, $P$. fonetana, $P$. guentheri and $P$. notosticta, falling sister to the genus Cophyla. The former group 
would have the name Mantipus Peters, 1883 available for it, while the latter would retain the name Plethodontohyla Boulenger, 1882. On the other hand, if the species with T- or Y-shaped terminal phalanges would result in a monophyletic group (i.e. if $P$. inguinalis were to move to the group containing $P$. notosticta, $P$. fonetana, $P$. guentheri and $P$. mihanika), the oldest available name for the terrestrial species with knobbed phalanges would be Phrynocara. The morphology of the genus combined with the latest available multi-gene phylogeny (Scherz et al. 2016a) suggests however that this group is an eclectic but monophyletic radiation, consisting of several species groups. However, due to the variable external morphology, ecological plasticity, conflicting phylogenetic studies and the availability of many old names and synonyms, an in depth phylogenetic analysis that will assess the species phylogenetic relationships and provide a taxonomic revision of the genus is needed.

\section{Acknowledgments}

We are grateful to the Malagasy authorities, in particular the Ministère de l'Environnement et des Forêts, for issuing research and export permits. We extend our thanks to Karen Freeman and Ingrid Porton of Madagascar Fauna and Flora Group. Fieldwork was financially supported by the Saint Louis Zoo's Field Research for Conservation program (FRC\# 12-12) of the Wildcare Institute and Gondwana Conservation and Research. We thank Chantal Misandeau and Lauric Reynes for sharing their photographs of the amphibians of Ambodiriana. The Institute for the Conservation of Tropical Environments (ICTE-MICET) provided crucial logistic support. We are grateful to the teams of the Muséum National d'Histoire Naturelle de Paris (France), the Naturmuseum Senckenberg in Frankfurt am Main (Germany) and the Mention Zoologie et Biodiversité Animale, Université d'Antananarivo (Madagascar) for the loan of material pertaining to this paper. We thank the reviewers for their useful comments that significantly improved the manuscript. We are indebted to Miguel Vences for having provided three unpublished POMC sequences used in this work. This work was funded by Portuguese National Funds through FCT - Foundation for Science and Technology under the IF/00209/2014/ CP1256/CT0011 Exploratory Research Project. Work of the authors over the past 25 years has been made possible by collaboration accords with the Universite d'Antananarivo (Mention Zoologie et Biodiversité Animale) and with the Parc Botanique et Zoologique de Tsimbazaza.

\section{References}

AmphibiaWeb (2018) http://amphibiaweb.org/ [accessed on 23 January 2018]

Andreone F, Vences M, Vieites DR, Glaw F, Meyer A (2005) Recurrent ecological adaptations revealed through a molecular analysis of the secretive cophyline frogs of Madagascar. Molecular Phylogenetics and Evolution 34(2): 315-322. http://dx.doi.org/10.1016/j. ympev.2004.10.013

Blommers-Schlösser RMA (1975) Observations on the larval development of some Malagasy frogs, with notes on their ecology and biology (Anura: Dyscophinae, Scaphiophryninae and Cophylinae). Beaufortia 24(309): 7-26.

Blommers-Schlösser RMA, Blanc CP (1991) Amphibiens (première partie). Faune de Madagascar 75: 1-379.

Boettger O (1913) Reptilien und Amphibien von Madagascar, den Inseln und dem Festland Ostafrikas. In Voeltzkow A (Ed.) Reise in Ost-Afrika in den Jahren 1903-1905 mit Mitteln der Hermann und Elise geb. Heckmann-Wentzel-Stiftung. Wissenschaftliche Ergebnisse. Systematischen Arbeiten 3(4): 269-376. Stuttgart, E. Schweizerbart.

Boulenger GA (1882) Catalogue of the Batrachia Salientia \& Ecaudata in the Collection of the British Museum. Second edition. Taylor and Francis, London.

Bruford MW, Hanotte O, Brookefield JFY, Burke T (1992) Single-locus and multilocus DNA fingerprint. In: Hoelzel AR (Ed.) Molecular Genetic Analysis of Populations: A Practical Approach. IRL Press, Oxford, 225-270.

Clement M, Posada D, Crandall KA (2000) TCS: a computer program to estimate gene genealogies. Molecular Ecology 9(10): 1657-1659. https://doi.org/10.1046/j.1365-294x.2000.01020.x

Darriba D, Taboada GL, Doallo R, Posada D (2012) jModelTest 2: more models. new heuristics and parallel computing. Nature Methods 9(8): 772-772. https://doi.org/10.1038/nmeth.2109

Dayrat B (2005) Towards integrative taxonomy. Biological Journal of the Linnean Society 85(3): 407-415. https://doi.org/10.1111/j.10958312.2005.00503.x

D’Cruze N, Köhler J, Vences M, Glaw F (2010) A new fat fossorial frog (Microhylidae: Cophylinae: Rhombophryne) from the rainforest of the Forêt d'Ambre Special Reserve, northern Madagascar. Herpetologica 66(2): 182-191. https://doi.org/10.1655/09-008R1.1

Emerson SB (1979) The ilio-sacral articulation in frogs: form and function. Biological Journal of the Linnean Society 11(2): 153-168. https://doi.org/10.1111/j.1095-8312.1979.tb00032.x

Frost DR, Grant T, Faivovich J, Bain RH, Haas A, Haddad CFB, De Sá RO, Channing A, Wilkinson M, Donnellan SC, Raxworthy CJ, Campbell JA, Blotto BL, Moler P, Drewes RC, Nussbaum RA, Lynch JD, Green DM, Wheeler WC (2006) The amphibian tree of life. Bulletin of the American Museum of Natural History 297: 1-370. https://doi.org/10.1206/0003-0090(2006)297[0001:TATOL]2.0.CO;2

Glaw F, Vences M (1992) A fieldguide to the amphibians and reptiles of Madagascar, 1st edition, Vences \& Glaw Verlag, Köln, 335 pp.

Glaw F, Vences M (2007a) Plethodontohyla guentheri, a new montane microhylid frog species from northeastern Madagascar. Mitteilungen aus dem Museum für Naturkunde in Berlin, Zoologische Reihe 83(Suppl. 1): 33-39. https://doi.org/10.1002/mmnz.200600023

Glaw F, Vences M (2007b) A field guide to the amphibians and reptiles of Madagascar, 3rd edition. Vences \& Glaw Verlag, Köln, 496 pp.

Glaw F, Köhler J, Bora P, Rabibisoa NHC, Ramilijaona O, Vences M (2007) Discovery of the genus Plethodontohyla (Anura: Microhylidae) in dry western Madagascar: description of a new species and biogeographic implications. Zootaxa 1577: 61-68. http://www.mapress.com/zootaxa/2007f/z01577p068f.pdf 
Glaw F, Köhler J, Vences M (2010) A new fossorial frog, genus Rhombophryne, from Nosy Mangabe Special Reserve, Madagascar. Zoosystematics and Evolution 86(2): 235-243. https://doi.org/10.1002/ zoos.201000006

Guibé J (1947) Contribution a l'etude du genre Mantipus. Mémoires de 1'Institut Scientifique de Madagascar 1: 76-80.

Guibé J (1952) Recherches sur les batraciens de Madagascar. Mémoires de 1'Institut Scientifique de Madagascar 7: 109-116.

Guibé J (1974) Batraciens nouveaux de Madagascar. Bulletin du Muséum national d'Histoire Naturelle Paris, 3rd series, 171: 1069-1192.

Guibé J (1975) Batraciens nouveaux de Madagascar. Bulletin du Muséum national d'Histoire Naturelle Paris, 3rd series, 323: 1081-1089.

Guibé J (1978) Les batraciens de Madagascar. Bonner zoologische Monographien 11: 1-140.

Hall TA (1999) BioEdit: a user-friendly biological sequence alignment editor and analysis program for Windows 95/98/NT. Nucleic Acids Symposium 41: 95-98. http://jwbrown.mbio.ncsu.edu/JWB/papers/1999Hall1.pdf

IUCN (2012) IUCN Red List Categories and Criteria: Version 3.1. IUCN, Gland, Switzerland and Cambridge, UK.

Kocher TD, Thomas WK, Meyer A, Edwards SV, Pääbo S, Villablanca FX, Wilson AC (1989) Dynamics of mitochondrial DNA evolution in mammals: amplification and sequencing with conserved primers. Proceedings of the National Academy of Sciences of the United States of America 86(16): 6196-6200. https://doi.org/10.1073/ pnas.86.16.6196

Köhler J, Jansen M, Rodríguez A, Kok PJR, Toledo LF, Emmrich M, Glaw F, Haddad CFB, Rödel MO, Vences M (2017) The use of bioacoustics in anuran taxonomy: theory, terminology, methods and recommendations for best practice. Zootaxa 4251(1): 1-124. https:// doi.org/10.11646/zootaxa.4251.1.1

Kumar S, Stecher G, Tamura K (2016) MEGA7: Molecular Evolutionary Genetics Analysis version 7.0 for bigger datasets. Molecular Biology and Evolution 33: 1870-1874. https://oi.org/10.1093/molbev/msw054

Lambert SM, Hutter CR, Scherz MD (2017) Diamond in the rough: a new species of fossorial diamond frog (Rhombophryne) from Ranomafana National Park, southeastern Madagascar. Zoosystematics and Evolution 93(1): 143-155. https://doi.org/10.3897/ zse.93.10188

Librado P, Rozas J (2009) DnaSP v5: A software for comprehensive analysis of DNA polymorphism data. Bioinformatics 25(11): 14511452. https://doi.org/10.1093/bioinformatics/btp187

Mocquard MF (1895) Sur une collection de reptiles recueillis à Madagascar par M.M. Alluaud et Belly. Bulletin de la Société philomatique de Paris, ser. 8: 112-136.

Mocquard MF (1901) Note préliminaire sur une collection de reptiles et de batraciens recueillis par M. Alluaud dans le sud de Madagascar. Bulletin du Muséum national d'Histoire Naturelle, Paris 7: 251-256.

Noble GK, Parker HW (1926) A synopsis of the brevicipitid toads of Madagascar. American Museum Novitates 232: 1-21. http://hdl. handle.net/2246/4206

Palumbi S, Martin A, Romano S, McMillan WO, Stice L, Grabowski G (1991) The simple fools guide to PCR. Version 2.0. Department of Zoology and Kewalo Marine Laboratory, University of Hawaii, Honolulu, HI.

Parker HW (1934) A Monograph of the Frogs of the Family Microhylidae. Trustees of the British Museum, London.
Peloso PLV, Frost DR, Richards SJ, Rodrigues MT, Donnellan S, Matsui M, Raxworthy CJ, Biju SD, Lemmon EM, Lemmon AR, Wheeler WC (2016) The impact of anchored phylogenomics and taxon sampling on phylogenetic inference in narrow-mouthed frogs (Anura, Microhylidae). Cladistics 32(2): 113-140. https://doi.org/10.1111/cla.12118

Perl RGB, Nagy ZT, Sonet G, Glaw F, Wollenberg KC, Vences M (2014) DNA barcoding Madagascar's amphibian fauna. Amphibia-Reptilia 35(2): 197-206. https://doi.org/10.1163/15685381-00002942

Peters WCH (1883) Über Mantipus und Phrynocara, zwei neue Batrachiergattungen aus dem Hinterlasse des Reisenden J. M. Hildebrandt von Madagascar. Sitzungsberichte der Akademie der Wissenschaften Königlich Preussischen zu Berlin 1883: 165-168.

Pyron RA, Wiens JJ (2011) A large-scale phylogeny of Amphibia including over 2800 species, and a revised classification of extant frogs, salamanders, and caecilians. Molecular Phylogenetics and Evolution 61(2): 543-583. https://doi.org/10.1016/j.ympev.2011.06.012

Rakotoarison A, Glaw F, Vieites DR, Raminosoa NR, Vences M (2012) Taxonomy and natural history of arboreal microhylid frogs (Platypelis) from the Tsaratanana Massif in northern Madagascar, with description of a new species. Zootaxa 3563(1): 1-25. https://doi. org/10.5281/zenodo. 215396

Rakotoarison A, Crottini A, Müller J, Rödel MO, Glaw F, Vences M (2015) Revision and phylogeny of narrow-mouthed treefrogs (Cophyla) from northern Madagascar: integration of molecular, osteological, and bioacoustic data reveals three new species. Zootaxa 3937(1): 61-89. https://doi.org/10.11646/zootaxa.3937.1.3

Rakotoarison A, Scherz MD, Glaw F, Köhler J, Andreone F, Franzen M, Glos J, Hawlitschek O, Jono T, Mori A, Ndriantsoa SH, Raminosoa Rasoamampionona N, Riemann JC, Rödel MO, Rosa GM, Vieites DR, Crottini A, Vences M (2017) Describing the smaller majority: Integrative taxonomy reveals twenty-six new species of tiny microhylid frogs (genus Stumpffia) from Madagascar. Vertebrate Zoology 67(3): 271-398.

Rambaut A, Drummond AJ (2007) Tracer v1.4. http://beast.bio.ed.ac. uk/Tracer [accessed 1 June 2011]

Ronquist F, Teslenko M, van der Mark P, Ayres DL, Darling A, Höhna S, Larget B, Liu L, Suchard MA, Huelsenbeck JP (2012) MrBayes 3.2: efficient Bayesian phylogenetic inference and model choice across a large model space. Systematic Biology 61(3): 539-542. https://doi.org/10.1093/sysbio/sys029

Rosa GM, Andreone F (2010) Bioacoustic data of the recently described Boophis calcaratus (Anura: Mantellidae: Boophinae), a cryptic treefrog from Eastern Madagascar. Zootaxa 2426: 61-64. http://www. mapress.com/zootaxa/2010/f/z02426p064f.pdf

Rosa GM, Noël J, Andreone F (2010) The advertisement call of Mantidactylus aerumnalis (Anura: Mantellidae), a terrestrial frog from the east coast of Madagascar. Salamandra 46(2): 98-100. http://www. salamandra-journal.com/index.php/home/contents/2010-vol-46/92rosa-g-m-j-noel-f-andreone/file

Rosa GM, Márquez M, Andreone F (2011) The astonishing calls of the frogs of Betampona. Museo Regionale di Scienze Naturali di Torino, Torino, Italy.

Rosa GM, Andreone F, Crottini A, Hauswaldt JS, Noël J, Rabibisoa NH, Randriambahiniarime MO, Rebelo R, Raxworthy CJ (2012) The amphibians of the relict Betampona low-elevation rainforest, eastern Madagascar: an application of the integrative taxonomy approach to biodiversity assessments. Biodiversity and Conservation 21(6): 15311559. https://doi.org/10.1007/s10531-012-0262-x 
Rosa GM, Crottini A, Noël J, Rabibisoa N, Raxworthy CJ, Andreone F (2014) A new phytotelmic species of Platypelis (Microhylidae: Cophylinae) from the Betampona Reserve, Eastern Madagascar. Salamandra 50(4): 201-214. http://www.salamandra-journal.com/ index.php/home/contents/2014-vol-50/378-rosa-g-m-a-crottini-jnoel-n-rabibisoa-c-j-raxworthy-f-andreone/file.

Scherz MD, Ruthensteiner B, Vences M, Glaw F (2014) A new microhylid frog, genus Rhombophryne, from northeastern Madagascar, and a re-description of $R$. serratopalpebrosa using micro-computed tomography. Zootaxa 3860(6): 547-560. https://doi.org/10.11646/ zootaxa.3860.6.3

Scherz MD, Rakotoarison A, Hawlitschek O, Vences M, Glaw F (2015a) Leaping towards a saltatorial lifestyle? An unusually long-legged new species of Rhombophryne (Anura, Microhylidae) from the Sorata massif in northern Madagascar. Zoosystematics and Evolution 91: 105-114. https://doi.org/10.3897/zse.91.4979

Scherz MD, Ruthensteiner B, Vieites DR, Vences M, Glaw F (2015b) Two new microhylid frogs of the genus Rhombophryne with superciliary spines from the Tsaratanana Massif in northern Madagascar. Herpetologica 71(4): 310-321. https://doi.org/10.1655/HERPETOLOGICA-D-14-00048

Scherz MD, Vences M, Rakotoarison A, Andreone F, Köhler J, Glaw F, Crottini A (2016a) Reconciling molecular phylogeny, morphological divergence and classification of Madagascan narrow-mouthed frogs (Amphibia: Microhylidae). Molecular Phylogenetics and Evolution 100: 372-381. https://doi.org/10.1016/j.ympev.2016.04.019

Scherz MD, Glaw F, Vences M, Andreone F, Crottini A (2016b) Two new species of terrestrial microhylid frogs (Microhylidae: Cophylinae: Rhombophryne) from northeastern Madagascar. Salamandra 52: 91-106. http://www.salamandra-journal.com/index.php/home/ contents/2016-vol-52/566-scherz-m-d-f-glaw-m-vences-f-andreone-a-crottini/file

Scherz MD, Hawlitschek O, Andreone F, Rakotoarison A, Vences M, Glaw F (2017) A review of the taxonomy and osteology of the Rhombophryne serratopalpebrosa species group (Anura: Microhylidae) from Madagascar, with comments on the value of volume rendering of micro-CT data to taxonomists. Zootaxa 4273: 301-340. https://doi.org/10.11646/zootaxa.4273.3.1

Stephens M, Smith NJ, Donnelly P (2001) A new statistical method for haplotype reconstruction from population data. American Journal of Human Genetics 68: 978-989. https://doi.org/10.1086/319501

Templeton AR, Crandall KA, Sing CF (1992) A cladistic analysis of phenotypic associations with haplotypes inferred from restriction endonuclease mapping and DNA sequence data. III. Cladogram estimation. Genetics 132(2): 619-633. https://www.ncbi.nlm.nih.gov/ pubmed/1385266

Trueb L (1968) Cranial osteology of the hylid frog, Smilisca baudini. University of Kansas Publications, Museum of Natural History 18: 11-35.

Trueb L (1973) Bones, frogs, and evolution. In: Vial JL (Ed.) Evolutionary biology of the anurans: Contemporary research on major problems. University of Missouri Press, USA, 65-132.

Vallan D, Glaw F, Vences M (2005) The calls of Pletodontohyla inguinalis from eastern Madagascar (Amphibia, Microhylidae). Spixiana 28(1): 91-93.

Vences M, Raxworthy CJ, Nussbaum RA, Glaw F (2003) New microhylid frog (Plethodontohyla) from Madagascar, with semiarboreal habits and possible parental care. Journal of Herpetology 37(4): 629-636. https://doi.org/10.1670/258-01A

Vences M, Thomas M, Bonett RM, Vieites DR (2005) Deciphering amphibian diversity through DNA barcoding: chances and challenges. Philosophical Transaction of the Royal Society of London Series B 360(1462): 1859-1868. https://doi.org/10.1098/rstb.2005.1717

Vences M, Köhler J, Crottini A, Glaw F (2010) High mitochondrial sequence divergence meets morphological and bioacoustic conservatism: Boophis quasiboehmei sp. nov., a new cryptic treefrog species from south-eastern Madagascar. Bonn zoological Bulletin 57(2): 241-255. https://www.yumpu.com/en/document/view/23181939/ high-mitochondrial-sequence-divergence-meets-morphological-andVieites DR, Min MS, Wake DB (2007) Rapid diversification and dispersal during periods of global warming by plethodontid salamanders. Proceedings of the National Academy of Sciences of the United States of America 104(50): 19903-19907. https://doi.org/10.1073/ pnas.0705056104

Vieites DR, Wollenberg KC, Andreone F, Köhler J, Glaw F, Vences M (2009) Vast underestimation of Madagascar's biodiversity evidenced by an integrative amphibian inventory. Proceedings of the National Academy of Sciences of the United States of America 106(20): 8267-8272. https://doi.org/10.1073/pnas.0810821106

Wollenberg KC, Vieites DR, van der Meijden A, Glaw F, Cannatella DC, Vences M (2008) Patterns of endemism and species richness in Malagasy cophyline frogs support a key role of mountainous areas for speciation. Evolution 62(8): 1890-1907. https://doi.org/10.1111/ j.1558-5646.2008.00420.x

\section{Supplementary material 1}

\section{PDF-embedded 3D model of the skeleton of Plethodontohyla alluaudi holotype (MNHN 1901.235)}

Authors: Adriana Bellati, Mark D. Scherz, Steven Megson, Sam Hyde Roberts, Franco Andreone, Gonçalo M. Rosa, Jean Noël, Jasmin E. Randrianirina, Mauro Fasola, Frank Glaw, Angelica Crottini

Data type: Adobe PDF file

Copyright notice: This dataset is made available under the Open Database License (http://opendatacommons. org/licenses/odbl/1.0/). The Open Database License $(\mathrm{ODbL})$ is a license agreement intended to allow users to freely share, modify, and use this Dataset while maintaining this same freedom for others, provided that the original source and author(s) are credited.

Link: https://doi.org/10.3897/zse.94.14698.suppl1

\section{Supplementary material 2}

\section{PDF-embedded 3D model of the skeleton of Plethodontohyla laevis holotype (SMF 4286)}

Authors: Adriana Bellati, Mark D. Scherz, Steven Megson, Sam Hyde Roberts, Franco Andreone, Gonçalo 
M. Rosa, Jean Noël, Jasmin E. Randrianirina, Mauro Fasola, Frank Glaw, Angelica Crottini

Data type: Adobe PDF file

Copyright notice: This dataset is made available under the Open Database License (http://opendatacommons. org/licenses/odb1/1.0/). The Open Database License $(\mathrm{ODbL})$ is a license agreement intended to allow users to freely share, modify, and use this Dataset while maintaining this same freedom for others, provided that the original source and author(s) are credited.

Link: https://doi.org/10.3897/zse.94.14698.supp12

\section{Supplementary material 3}

\section{PDF-embedded 3D model of the skeleton of Plethodontohyla laevis tsianovohensis holo- type (MNHN 1936.47)}

Authors: Adriana Bellati, Mark D. Scherz, Steven Megson, Sam Hyde Roberts, Franco Andreone, Gonçalo M. Rosa, Jean Noël, Jasmin E. Randrianirina, Mauro Fasola, Frank Glaw, Angelica Crottini

Data type: Adobe PDF file

Copyright notice: This dataset is made available under the Open Database License (http://opendatacommons. org/licenses/odbl/1.0/). The Open Database License $(\mathrm{ODbL})$ is a license agreement intended to allow users to freely share, modify, and use this Dataset while maintaining this same freedom for others, provided that the original source and author(s) are credited.

Link: https://doi.org/10.3897/zse.94.14698.suppl3

\section{Supplementary material 4}

\section{PDF-embedded 3D model of the skeleton of ZSM 3/2002, a specimen of an undescribed Rhombophryne species formerly called Rhombophryne 'alluaudi'}

Authors: Adriana Bellati, Mark D. Scherz, Steven Megson, Sam Hyde Roberts, Franco Andreone, Gonçalo M. Rosa, Jean Noël, Jasmin E. Randrianirina, Mauro Fasola, Frank Glaw, Angelica Crottini

Data type: Adobe PDF file

Copyright notice: This dataset is made available under the Open Database License (http://opendatacommons. org/licenses/odbl/1.0/). The Open Database License $(\mathrm{ODbL})$ is a license agreement intended to allow users to freely share, modify, and use this Dataset while maintaining this same freedom for others, provided that the original source and author(s) are credited.

Link: https://doi.org/10.3897/zse.94.14698.suppl4

\section{Supplementary material 5}

\section{PDF-embedded 3D model of the skeleton of MRSN A6340, a specimen assigned to Plethodontohyla laevis}

Authors: Adriana Bellati, Mark D. Scherz, Steven Megson, Sam Hyde Roberts, Franco Andreone, Gonçalo M. Rosa, Jean Noël, Jasmin E. Randrianirina, Mauro Fasola, Frank Glaw, Angelica Crottini

Data type: Adobe PDF file

Copyright notice: This dataset is made available under the Open Database License (http://opendatacommons. org/licenses/odbl/1.0/). The Open Database License $(\mathrm{ODbL})$ is a license agreement intended to allow users to freely share, modify, and use this Dataset while maintaining this same freedom for others, provided that the original source and author(s) are credited.

Link: https://doi.org/10.3897/zse.94.14698.suppl5

\section{Supplementary material 6}

\section{PDF-embedded 3D model of the skeleton of ZSM 89/2004, a specimen assigned to Plethodontohyla alluaudi}

Authors: Adriana Bellati, Mark D. Scherz, Steven Megson, Sam Hyde Roberts, Franco Andreone, Gonçalo M. Rosa, Jean Noël, Jasmin E. Randrianirina, Mauro Fasola, Frank Glaw, Angelica Crottini

Data type: Adobe PDF file

Copyright notice: This dataset is made available under the Open Database License (http://opendatacommons. org/licenses/odbl/1.0/). The Open Database License $(\mathrm{ODbL})$ is a license agreement intended to allow users to freely share, modify, and use this Dataset while maintaining this same freedom for others, provided that the original source and author(s) are credited.

Link: https://doi.org/10.3897/zse.94.14698.suppl6 